\title{
Consistency limits and compaction characteristics of clay soils containing rubber waste
}

\section{Amin Soltani}

PhD student, School of Civil, Environmental and Mining Engineering, The University of Adelaide, Adelaide, SA, Australia (corresponding author: amin.soltani@adelaide.edu.au) (Orcid:0000-0002-0483-7487)

\section{An Deng}

Senior Lecturer, School of Civil, Environmental and Mining Engineering, The University of Adelaide, Adelaide, SA, Australia

\author{
Abbas Taheri \\ Senior Lecturer, School of Civil, Environmental and Mining Engineering, \\ The University of Adelaide, Adelaide, SA, Australia \\ Asuri Sridharan \\ Professor Emeritus, Department of Civil Engineering, Indian Institute of \\ Science, Bangalore, India; Honorary Research Scientist, Indian National \\ Science Academy, New Delhi, India
}

The aim of the study reported in this paper was to develop practical correlative models capable of predicting the compaction characteristics of clay soils blended with rubber from waste vehicle tyres. Four different clay soils, ranging from intermediate to high plasticity, were adopted for the test programme and each was blended with four different percentages of ground rubber waste. The test programme consisted of cone penetration (consistency limits) and standard Proctor compaction tests. As a result of ground rubber inclusion, the consistency limits and compaction characteristics all exhibited a linear decreasing trend with increase in rubber content. The rate of decrease, however, was greater for the high-plasticity clays. Simple correlative models, linking the compaction characteristics to the consistency limits, were suggested and validated by statistical techniques. The proposed models provide a practical procedure towards predicting the compaction characteristics of ground rubber-clay blends without the hurdles of conducting laboratory compaction tests, and thus can be implemented in practice for preliminary assessments.

\section{Notation}

$G_{\mathrm{sm}} \quad$ average specific gravity of ground rubber-clay mix

$G_{\text {sr }} \quad$ specific gravity of ground rubber

$G_{\mathrm{ss}} \quad$ specific gravity of soil solids

$I_{\mathrm{F}} \quad$ flow index

$I_{\mathrm{P}} \quad$ plasticity index

$R^{2} \quad$ coefficient of determination

$R_{\mathrm{c}} \quad$ rubber content (by weight)

$R_{\mathrm{c}}^{\mathrm{M}} \quad$ median rubber content

$w \quad$ water content

$w_{\mathrm{L}} \quad$ liquid limit

$w_{\text {opt }} \quad$ optimum water content

$w_{\mathrm{P}} \quad$ plastic limit

$w_{\mathrm{P}}^{\mathrm{M}} \quad$ plastic limit corresponding to $R_{\mathrm{c}}^{\mathrm{M}}$

$w_{\text {Po }} \quad$ plastic limit for the virgin clay

$\gamma_{\mathrm{d}} \quad$ dry unit weight

$\gamma_{\text {dmax }} \quad$ maximum dry unit weight

$\gamma_{\mathrm{dP}} \quad$ dry unit weight at plastic limit

$\gamma_{\mathrm{w}} \quad$ unit weight of water

$\delta \quad$ cone penetration

$\eta \quad$ coefficient of plastic limit reduction

$\chi \quad$ average ratio of $I_{\mathrm{P}}$ to $I_{\mathrm{F}}$

\section{Introduction}

The design and construction of geostructures often necessitate incorporating low-graded clay soils, with high moisture susceptibility (and plasticity) and low bearing capacity, in the construction. Common solutions to counteract the adversities associated with such soils include soil replacement (i.e. replacing the poor-quality clay soil with desired quarried materials) or attempting to improve the problematic soil by means of stabilisation techniques. Currently, two stabilisation schemes are in vogue for clay soils - namely, chemical and mechanical stabilisation (Soltani et al., 2017a). The chemical scheme makes use of chemical binders, which initiate a series of short- and long-term chemical reactions in the clay-binder medium, thereby amending the soil fabric into a coherent matrix of improved mechanical performance. Common binders include agents of traditional (e.g. cement, lime and fly ash) or non-traditional (e.g. polymers, resins and sulfonated oils) categories, both of which have been well documented in the literature (e.g. Estabragh et al., 2013, 2014; Georgees et al., 2015; Jha and Sivapullaiah, 2016; Mirzababaei et al., 2009; Soltani et al., 2017b). The mechanical technique often involves the placement of randomly or specifically engineered reinforcements (e.g. natural and synthetic fibres) in the soil regime, thereby engendering a spatial three-dimensional reinforcement network in favour of weaving (or interlocking) the soil grains into a unitary mass of improved mechanical performance (e.g. Estabragh et al., 2016; Mirzababaei et al., 2017, 2018; Soltani et al., 2018a; Tang et al., 2010; Wang et al., 2017). Lately, many developed and developing countries have initiated the transition towards 'sustainable infrastructure', a concept which fosters the beneficial reuse of solid wastes and/or industrial by-products as a replacement for conventional quarried materials (such as sand) and/or stabilisation agents, thereby conserving natural resources as well as reducing the level of greenhouse gas emissions. Promising replacements, based on recent studies, include recycled tyre rubbers, waste textiles, 
demolition wastes, kiln and quarry dusts, and silicate/calcium geopolymers (e.g. Al-Amoudi et al., 2017; Alazigha et al., 2016; Arulrajah et al., 2017; Kua et al., 2017; Mirzababaei et al., 2013a, 2013b; Soosan et al., 2005).

Waste tyre rubbers are being generated at an increasing rate throughout the world. Such materials are bulky in nature, owing to their low weight-to-volume ratio, and thus consume valuable landfill space upon disposal. As such, local communities and governmental agencies have been increasingly encouraged to recycle and hence reuse waste tyres as part of the infrastructure system. The rubber-soil blend is showing great promise in several respects - for example, reduced unit weight, enhanced strength and ductility, increased permeability and reduced moisture susceptibility (i.e. swell-shrink capacity), which can facilitate the production and placement of sustainable earth fills such as road and railway embankments (e.g. Cabalar et al., 2014; Cetin et al., 2006; Özkul and Baykal, 2007; Perez et al., 2017; Signes et al., 2016; Soltani et al., 2018b, 2018c; Srivastava et al., 2014; Trouzine et al., 2012; Wang et al., 2018; Yadav and Tiwari, 2017a, 2017b). When placed in a flowable condition, the rubber-soil blend outperforms conventional soil backfills by enabling the placement of particles into any irregular or inaccessible space without significant compaction efforts (ACI R229 (ACI, 2013)). The advantages of rubber-mixed soils in engineering performance, which natural soils rarely exhibit, suggest a promising path towards sustainability without compromising performance. Although these materials are promising, the leaching of heavy metals from rubber particles (into the soil mass and/or water bodies) could raise some environmental concerns. In such cases, most documented studies have reported that the degree of soil and water contamination both remain within the allowable limits provided by various health and environmental agencies. When paired with coarsegrained soils, however, the rubber-soil blend should be stabilised by means of chemical binders to meet the required environmental standards (see Yadav and Tiwari (2017c) for more details).

A review of the literature indicates a rather common emphasis on the application of coarse-grained tyre rubber material in the form of fibres, shreds and aggregates. Such materials, however, would be associated with implementation difficulties when dealing with cohesive clay soils (e.g. mixing difficulties and hence non-uniform distribution of rubber particles in the soil regime). As such, types of recycled tyres less often considered for this purpose, such as fine ground rubber (GR), offer the advantage of better workability, and thus demand further investigation. Quite clearly, a vital step towards the production and placement of suitable rubber-clay earth fills is compaction. In this context, the maximum dry unit weight has been reported to decrease with increase in rubber content, while the reported trends for optimum water content still remain rather inconsistent (e.g. Al-Tabbaa et al., 1997; Cetin et al., 2006; Kalkan, 2013; Priyadarshee et al., 2018; Seda et al., 2007). In comparison, limited studies (e.g. Cetin et al., 2006; Srivastava et al., 2014; Trouzine et al., 2012) have been conducted on the consistency limits, the results of which have yet been systematically correlated with other geotechnical properties such as the compaction characteristics. With rubber-soil blends gaining ground as a viable geomaterial in practice, the need for an efficient and simple tool to adequately predict its performance, in terms of compaction, arises as an inevitable necessity. If developed, such a predictive toolbox would help the practising engineer to arrive at reliable rubber-soil design choices without the hurdles of conducting time-consuming laboratory compaction tests. Although numerous attempts have been made to correlate the compaction characteristics with the consistency limits for natural fine-grained soils (e.g. Blotz et al., 1998; Di Matteo et al., 2009; Gurtug and Sridharan, 2002, 2004; Gurtug et al., 2018; Nagaraj et al., 2015; Pandian et al., 1997; Pillai and Vinod, 2016; Sivrikaya et al., 2008; Sridharan and Nagaraj, 2005), such correlative models have yet to be developed for rubber-mixed soils.

In this study, a series of cone penetration (consistency limits) and standard Proctor compaction tests were carried out on various ground rubber-clay (GRC) blends (prepared with four different clay soils) to generate a reliable database allowing for the development of simple correlative models capable of predicting the compaction characteristics of GRC blends as a function of the composite's consistency limits. The models proposed in the present study provide a practical procedure towards predicting the compaction characteristics of GRC blends without the need for conducting time-consuming compaction tests.

\section{Materials}

\subsection{Clay soils}

Four different soils consisting of both natural and commercial soils, covering a wide range of plasticity characteristics, were adopted for the experimental programme. The natural soils, hereafter denoted as soils $\mathrm{RC} 1$ and $\mathrm{RC} 2$, consisted of reddishbrown clays sourced from a landfill site located at Adelaide, South Australia. The commercial soils were supplied by a local manufacturer, and included kaolinite (hereafter termed soil $\mathrm{K}$ ) and a mixture of $85 \%$ kaolinite and $15 \%$ sodium-activated bentonite (hereafter termed soil KB). The physical and mechanical properties of the soils, determined as per relevant ASTM and Australian standards, are summarised in Table 1. The liquid limit $w_{\mathrm{L}}$ and plasticity index $I_{\mathrm{P}}$ were measured as $w_{\mathrm{L}}=44 \%$ and $I_{\mathrm{P}}=22 \%$ for soil $\mathrm{K}$, and $w_{\mathrm{L}}=47 \%$ and $I_{\mathrm{P}}=29 \%$ for soil $\mathrm{RC} 1$, from which both soils were characterised as 'clay with intermediate plasticity' (CI) in accordance with the Unified Soil Classification System (USCS). The soils KB and $\mathrm{RC} 2$, however, were graded as 'clay with high plasticity' $(\mathrm{CH})$, exhibiting $w_{\mathrm{L}}$ and $I_{\mathrm{P}}$ values of $59 \%$ and $31 \%$ for soil $\mathrm{KB}$, and $78 \%$ and $57 \%$ for soil $\mathrm{RC} 2$, respectively. 
Table 1. Physical and mechanical properties of the clay soils

\begin{tabular}{|c|c|c|c|c|c|}
\hline Properties & Soil $\mathrm{K}$ & Soil RC1 & Soil KB & Soil RC2 & Standard designation \\
\hline Specific gravity, $G_{\text {ss }}$ & $2 \cdot 69$ & $2 \cdot 67$ & $2 \cdot 71$ & $2 \cdot 72$ & ASTM D854-14 (ASTM, 2014) \\
\hline \multicolumn{6}{|l|}{ Grain-size distribution } \\
\hline Clay $(<2 \mu \mathrm{m}): \%$ & 49 & 37 & 53 & 44 & \multirow[t]{5}{*}{ ASTM D422-07 (ASTM, 2007) } \\
\hline Silt $(2-75 \mu \mathrm{m}): \%$ & 50 & 32 & 46 & 36 & \\
\hline Fine sand $(0.075-0.425 \mathrm{~mm}): \%$ & 1 & 19 & 1 & 14 & \\
\hline Medium sand (0.425-2 mm): \% & 0 & 8 & 0 & 5 & \\
\hline Coarse sand $(2-4.75 \mathrm{~mm}): \%$ & 0 & 5 & 0 & 1 & \\
\hline \multicolumn{6}{|l|}{ Consistency limits and classification } \\
\hline Liquid limit, $w_{\mathrm{L}}: \%$ & 44 & 47 & 59 & 78 & AS $1289 \cdot 3 \cdot 9 \cdot 1-15^{\mathrm{a}}(\mathrm{SA}, 2015)$ \\
\hline Plastic limit, $W_{p}: \%$ & 22 & 18 & 28 & 21 & AS $1289 \cdot 3 \cdot 2 \cdot 1-09^{b}(S A, 2009)$ \\
\hline Plasticity index, $I_{P}\left(=W_{L}-W_{P}\right): \%$ & 22 & 29 & 31 & 57 & AS $1289 \cdot 3 \cdot 3 \cdot 1-09$ (SA, 2009) \\
\hline USCS classification & $\mathrm{Cl}^{\mathrm{C}}$ & $\mathrm{Cl}$ & $\mathrm{CH}^{\mathrm{d}}$ & $\mathrm{CH}$ & ASTM D2487-11 (ASTM, 2011) \\
\hline \multicolumn{6}{|l|}{ Compaction characteristics } \\
\hline Optimum water content, $w_{\text {opt }}: \%$ & 21 & 16 & 25 & 19 & \multirow[t]{2}{*}{ ASTM D698-12 (ASTM, 2012) } \\
\hline Maximum dry unit weight, $\gamma_{\text {dmax }}: \mathrm{kN} / \mathrm{m}^{3}$ & $15 \cdot 45$ & $16 \cdot 41$ & $14 \cdot 61$ & $15 \cdot 84$ & \\
\hline
\end{tabular}

${ }^{\text {a } C o n e ~ p e n e t r a t i o n ~ m e t h o d ~(s e e ~ S e c t i o n ~} 3.1$ for details)

${ }^{b}$ Conventional rolling thread method (see Section 3.1 for details)

${ }^{c}$ Clay with intermediate plasticity

${ }^{\mathrm{d} C l a y}$ with high plasticity

\subsection{Ground rubber}

Commercially available GR, supplied by a local distributor, was used as the reinforcing agent. The conventional grain-size (or sieve) analysis, carried out in accordance with the ASTM D422-07 (ASTM, 2007) standard, indicated that GR is similar in size to medium-fine sand, with particles ranging between $1.18 \mathrm{~mm}$ and $75 \mu \mathrm{m}$. The particle diameters corresponding to 10,30 and $60 \%$ finer were measured as $D_{10}=0.182 \mathrm{~mm}$, $D_{30}=0.334 \mathrm{~mm}$ and $D_{60}=0.513 \mathrm{~mm}$. The uniformity (i.e. $C_{\mathrm{u}}=$ $\left.D_{60} / D_{10}\right)$ and curvature (i.e. $C_{\mathrm{c}}=D_{30}^{2} / D_{10} D_{60}$ ) coefficients were therefore obtained as $C_{\mathrm{u}}=2 \cdot 81$ and $C_{\mathrm{c}}=1 \cdot 20$, from which GR was classified as 'poorly graded' in accordance with the USCS criteria. Figure 1 depicts microscopic micrographs of the rubber particles at three different magnification ratios
(Figure 1(a): $1 \times$ magnification; Figure 1(b): $50 \times$ magnification; and Figure 1(c): $200 \times$ magnification). As shown in Figure 1(b), the rubber particles are non-spherical and highly irregular in shape. Moreover, a series of cavity-like micro-cracks are distributed along the rubber's surface (see Figure 1(c)), thus making for a rough surface texture. Such surface features may potentially promote adhesion and/or induce interfacial friction between the rubber particles and the soil grains, thereby altering the soil fabric into a coherent matrix of enhanced mechanical performance (Soltani et al., 2018b). The physical properties and chemical composition of GR, as supplied by the manufacturer, are provided in Table 2. The specific gravity of GR was found to be $G_{\text {sr }}=1.09$, which is lower by two-fold approximately than the standard value of $G_{\mathrm{ss}}=2 \cdot 65$ reported for most soils.

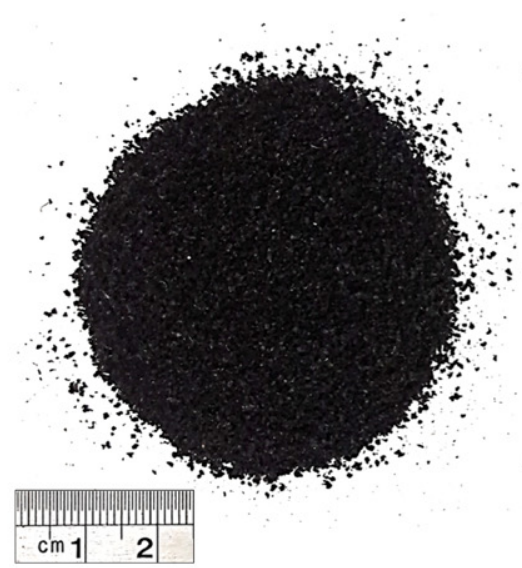

(a)

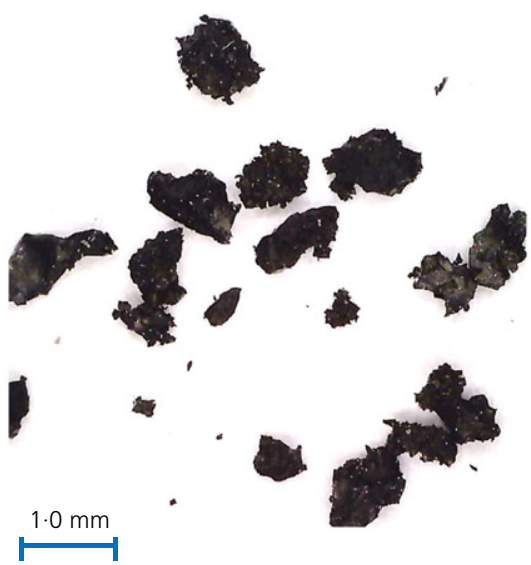

(b)

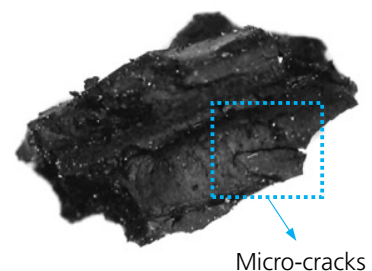

$0.2 \mathrm{~mm}$

Figure 1. Ground rubber (GR) particles at different magnification ratios (modified from Soltani et al., 2018b): (a) 1× magnification; (b) $50 \times$ magnification; (c) 200× magnification 
Table 2. Physical properties and chemical composition of GR

\begin{tabular}{|c|c|}
\hline Properties & Value/description \\
\hline \multicolumn{2}{|l|}{ Physical properties } \\
\hline Solubility in water & Insoluble \\
\hline Water adsorption & Negligible $(<4 \%)$ \\
\hline Resistance to acid/alkaline & Excellent \\
\hline Softening point: ${ }^{\circ} \mathrm{C}$ & 170 \\
\hline Specific gravity, $G_{s r}$ & 1.09 \\
\hline \multicolumn{2}{|l|}{ Grain-size distribution and classification ${ }^{a}$} \\
\hline$D_{10}: \mathrm{mm}^{\mathrm{b}}$ & $0 \cdot 182$ \\
\hline$D_{30}: \mathrm{mm}$ & 0.334 \\
\hline$D_{50}: \mathrm{mm}$ & 0.478 \\
\hline$D_{60}: \mathrm{mm}$ & 0.513 \\
\hline Coefficient of uniformity, $C_{u}{ }^{c}$ & $2 \cdot 81$ \\
\hline Coefficient of curvature, $C_{c}^{d}$ & $1 \cdot 20$ \\
\hline USCS classification & Poorly graded sand (SP) \\
\hline \multicolumn{2}{|l|}{ Chemical composition } \\
\hline Styrene-butadiene copolymer: \% & 55 \\
\hline Acetone extract: \% & $5-20$ \\
\hline Carbon black: \% & $25-35$ \\
\hline Zinc oxide: \% & $2-3$ \\
\hline Sulfur: \% & $1-3$ \\
\hline
\end{tabular}

${ }^{a}$ ASTM D422-07 (ASTM, 2007) method

${ }^{\mathrm{b}}$ Particle diameter corresponding to $10 \%$ finer

${ }^{c} C_{\mathrm{u}}=D_{60} / D_{10}$

${ }^{\mathrm{d}} C_{\mathrm{c}}=D_{30}^{2} / D_{10} D_{60}$

\section{Test programme}

Each of the four soil choices - namely, soils K, RC1, KB and $\mathrm{RC} 2$ - was blended with GR at four varying rubber contents (defined as GR to dry soil weight ratio) - that is, $R_{\mathrm{c}}=5,10$, 20 and $30 \%$ - and further tested for consistency limits and compaction characteristics. Hereafter, a simple coding system, defined as $\mathrm{KR} x, \operatorname{RC} 1 \mathrm{R} x, \mathrm{KBR} x$ and $\mathrm{RC} 2 \mathrm{R} x$ (where $\mathrm{R} x=x \%$ GR), will be adopted to designate the various mix designs. As a consequence of rubber particles floating in water, standard procedures outlined in ASTM D854-14 (ASTM, 2014) for measuring the specific gravity of solids were not applicable. Therefore, the specific gravity for various GRC blends was estimated by the following theoretical relationship (Soltani et al., 2018b)

1. $G_{\mathrm{sm}}=\frac{G_{\mathrm{ss}} G_{\mathrm{sr}}\left(W_{\mathrm{s}}+W_{\mathrm{r}}\right)}{W_{\mathrm{s}} G_{\mathrm{sr}}+W_{\mathrm{r}} G_{\mathrm{ss}}}$

where $G_{\mathrm{sm}}$ is the average specific gravity of GRC blends; $W_{\mathrm{s}}$ is the weight of dry soil; $W_{\mathrm{r}}$ is the weight of GR; $G_{\mathrm{ss}}$ is the specific gravity of soil solids (see Table 1); and $G_{\text {sr }}$ is the specific gravity of GR particles $(=1 \cdot 09)$.

\subsection{Consistency limits}

The virgin clays and various GRC blends were tested for consistency limits - namely, the liquid limit $w_{\mathrm{L}}$, plastic limit $w_{\mathrm{P}}$ and plasticity index $I_{\mathrm{P}}\left(=w_{\mathrm{L}}-w_{\mathrm{P}}\right)$, following the Australian code of practice (see relevant standard designations in Table 1). The liquid limit was obtained by means of the cone penetration method. The weight and conical angle of the cone were $80 \mathrm{~g}$ and $30^{\circ}$, respectively. The required amount of material (either virgin or GR-blended clay) was divided into six equal portions, each portion paired with a predetermined amount of water, and thoroughly mixed by mechanical effort to obtain slurries of uniform consistency. The resulting slurries where then remoulded into rigid cups, measuring $53 \mathrm{~mm}$ in diameter and $40 \mathrm{~mm}$ height, and placed in contact with the cone penetrometer for testing. The cone was allowed to freely penetrate into each sample for approximately $5 \mathrm{~s}$. The depth of penetration was measured by means of a digital dial gauge to the nearest $0.1 \mathrm{~mm}$. As a result of the test, a linear change in water content $w$ against the corresponding cone penetration $\delta$, commonly referred to as the flow curve, can be observed. Test results are plotted over the $w-\log _{10} \delta$ space, the slope of which is defined as the flow index - that is, $I_{\mathrm{F}}=\Delta w / \Delta \log _{10} \delta$ (Sridharan et al., 1999). Furthermore, the water content at which the cone penetration reaches $\delta=20 \mathrm{~mm}$ is taken as the liquid limit.

The rolling thread method is currently in vogue for direct measurement of the plastic limit. The water content at which a mass of soil (or material) begins to crumble when manually rolled into a thread of approximately $3.2 \mathrm{~mm}$ (dia.) is taken as the plastic limit. Quite clearly, the rolling thread method is highly subjective and therefore inevitably biased by personal judgements, which leads to inconsistent and often non-reproducible results among different operators. Moreover, it has been the authors' experience that this particular methodology would not be suitable for geomaterials containing notable non-plastic hydrophobic (i.e. low water adsorption capacity) fractions (despite the geomaterial's plastic response in the presence of water). The rubber's elastic character and hydrophobic nature make for a rather difficult, although possible, implementation of the conventional rolling thread technique. Although the rubber inclusion would most certainly lead to a reduced plastic limit, it is not possible to arrive at a certain/unique value with confidence following the current methodology. Such difficulties are essentially similar to those encountered for natural soils containing notable fractions of sand and silt, which have been well documented in the literature (e.g. Prakash and Sridharan, 2006, 2012). Among the available experimental alternatives for indirect measurement of the plastic limit, the flow index method suggests a rather practical and objective scheme, which is also supported by robust empirical observations as well as solid fundamental evidence (see Sridharan et al. (1999) for details). The flow index method states that the plasticity index is proportional to the flow index (obtained from the cone penetration test) - that is, $I_{\mathrm{P}} \propto I_{\mathrm{F}}$, and thus can be estimated by

\section{2. $\quad I_{\mathrm{P}}=\chi I_{\mathrm{F}}$}

where $\chi=$ empirical coefficient 
Therefore, the plastic limit can be estimated with a known liquid limit (obtained from the cone penetration test) by

$$
\text { 3. } w_{\mathrm{P}}=w_{\mathrm{L}}-\chi I_{\mathrm{F}}
$$

The empirical coefficient $\chi$ falls between $0 \cdot 71$ and $0 \cdot 74$, which was calibrated based on conventional rolling thread tests conducted on 121 soil samples of widely varying plasticity characteristics and geological origin (Sridharan et al., 1999). As a typical example, and to provide further verification of $\chi=0 \cdot 71-0 \cdot 74$, Figure 2 illustrates the variations of the plasticity index $I_{\mathrm{P}}\left(I_{\mathrm{P}}=w_{\mathrm{L}}-w_{\mathrm{B}}\right.$ where $w_{\mathrm{P}}=$ plastic limit obtained by the rolling thread method) against the flow index $I_{\mathrm{F}}$ for the virgin clays used in the present study. As demonstrated in the figure, a perfect correlation in the form of $I_{\mathrm{P}}=0.715 I_{\mathrm{F}}$ (with $\left.R^{2}=0.997\right)$ can be obtained between the plasticity and flow indices, which complies well with that suggested by Sridharan et al. (1999). Therefore, to avoid the difficulties associated with implementing the conventional rolling thread technique to various GRC blends, the plastic limit for both the virgin clays and various GRC blends was estimated by means of Equation 3 (with $\chi=0 \cdot 715$ ). Hereafter, the term plastic limit will refer to that obtained by means of the flow index method.

\subsection{Compaction studies}

Standard Proctor compaction tests were carried out on the virgin clays and various GRC blends in accordance with the ASTM D698-12 (ASTM, 2012) standard. The required amount of material (either virgin or GR-blended clay) was divided into six equal portions, each portion paired with a predetermined amount of water, and thoroughly mixed by hand. Extensive care was taken to pulverise the lumped particles, aiming for homogeneity of the mixtures. The moist mixtures

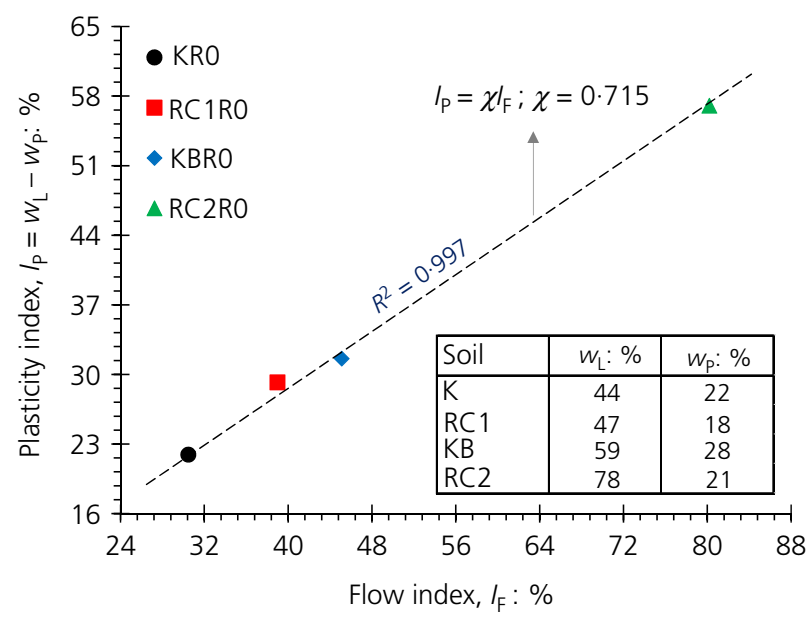

Figure 2. Variations of the conventional plasticity index plotted against the flow index for the virgin clays were sealed in plastic bags and allowed to cure for a period of $24 \mathrm{~h}$, ensuring even distribution of moisture throughout the composite mass. The cured mixtures were then subjected to the conventional standard Proctor compaction test to arrive at the dry unit weight-water content relationship, and thus quantify the optimum water content and the maximum dry unit weight.

\section{Statistical analysis}

The consistency limits, obtained as per Section 3.1, were each independently plotted against the corresponding optimum water contents, and further examined for single-coefficient linear correlations - that is, $w_{\mathrm{opt}}=\beta x$ ( $w_{\mathrm{opt}}$ is the optimum water content; $x=w_{\mathrm{L}}, w_{\mathrm{P}}$ or $I_{\mathrm{P}}$; and $\beta$ is the regression coefficient or fitting parameter). The most appropriate consistency parameter (capable of adequately estimating the optimum water content for various GRC blends) was then selected and coupled with basic volume-mass relations to arrive at a semi-empirical relationship for the maximum dry unit weight. The accuracy of the proposed correlative models for both the optimum water content and the maximum dry unit weight was then examined by means of statistical fit-measure indices.

\section{Results and discussion}

\subsection{Effect of GR on consistency limits}

The flow curves for the virgin clays and various GRC blends prepared with soils $\mathrm{K}, \mathrm{RC} 1, \mathrm{~KB}$ and $\mathrm{RC} 2$ are provided in Figures 3(a), 3(b), 3(c) and 3(d), respectively. As a result of GR inclusion, the flow curve exhibited a major downward shift over the $w-\log _{10} \delta$ space ( $w$ is the water content and $\delta$ is the cone penetration), indicating a significant reduction in the liquid limit (compare the water contents at $\delta=20 \mathrm{~mm}$ ). Meanwhile, the slope of the flow curve was also observed to decrease with increase in rubber content, leading to a notable reduction in the flow index $I_{\mathrm{F}}$ and hence the plasticity index $I_{\mathrm{P}}$ $\left(I_{\mathrm{P}}=0 \cdot 715 I_{\mathrm{F}}\right)$. As a typical case, the virgin clay $\mathrm{KB}$ resulted in $I_{\mathrm{F}}=45 \cdot 12 \%$, while the inclusion of $5,10,20$ and $30 \%$ GR resulted in $I_{\mathrm{F}}=43 \cdot 23 \%, 42 \cdot 00 \%, 40 \cdot 67 \%$ and $37 \cdot 74 \%$, respectively (see Figure 3(c)).

Figures 4(a), 4(b), 4(c) and 4(d) illustrate the variations of the consistency limits - namely, the liquid limit $w_{\mathrm{L}}$, plastic limit $w_{\mathrm{P}}\left(w_{\mathrm{P}}=w_{\mathrm{L}}-0 \cdot 715 I_{\mathrm{F}}\right)$ and plasticity index $I_{\mathrm{P}}\left(I_{\mathrm{P}}=0 \cdot 715 I_{\mathrm{F}}\right)$, against rubber content $R_{\mathrm{c}}$ for the virgin clays and various GRC blends prepared with soils $\mathrm{K}, \mathrm{RC} 1, \mathrm{~KB}$ and $\mathrm{RC} 2$, respectively. The higher the rubber content the lower the consistency limits, following a linear monotonic decreasing trend. As a typical case, the virgin clay $\mathrm{KB}$ resulted in $w_{\mathrm{L}}=59 \%$, while the inclusion of 5, 10, 20 and $30 \%$ GR resulted in $w_{\mathrm{L}}=57,53,51$ and $46 \%$, respectively (see Figure $4(\mathrm{c})$ ). The rate of decrease in $w_{\mathrm{L}}, w_{\mathrm{P}}$ and $I_{\mathrm{P}}$ with respect to $R_{\mathrm{c}}-$ represented by the slope of a typical linear trend line fitted through the desired dataset (i.e. $\Delta y / \Delta R_{\mathrm{c}}$, where $y=w_{\mathrm{L}}, w_{\mathrm{P}}$ or $I_{\mathrm{P}}$ ) - was observed to be dependent on the type of soil, with 


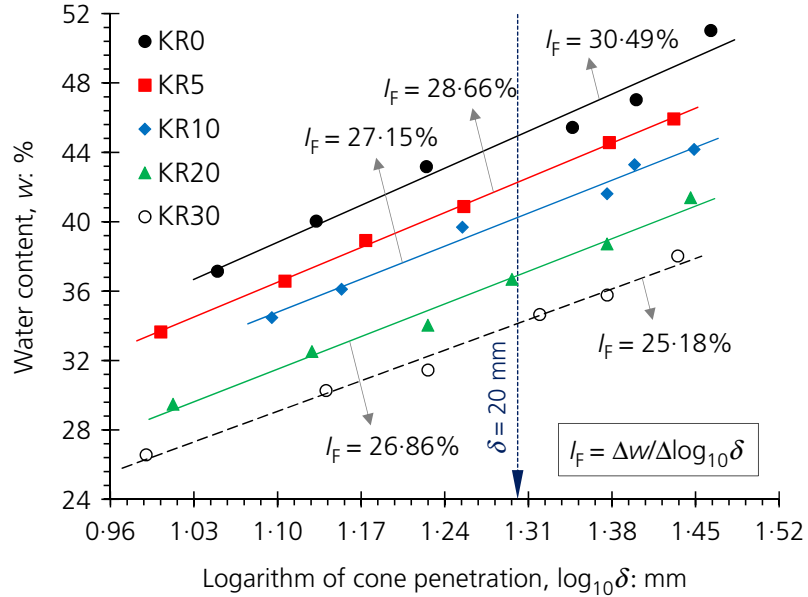

(a)

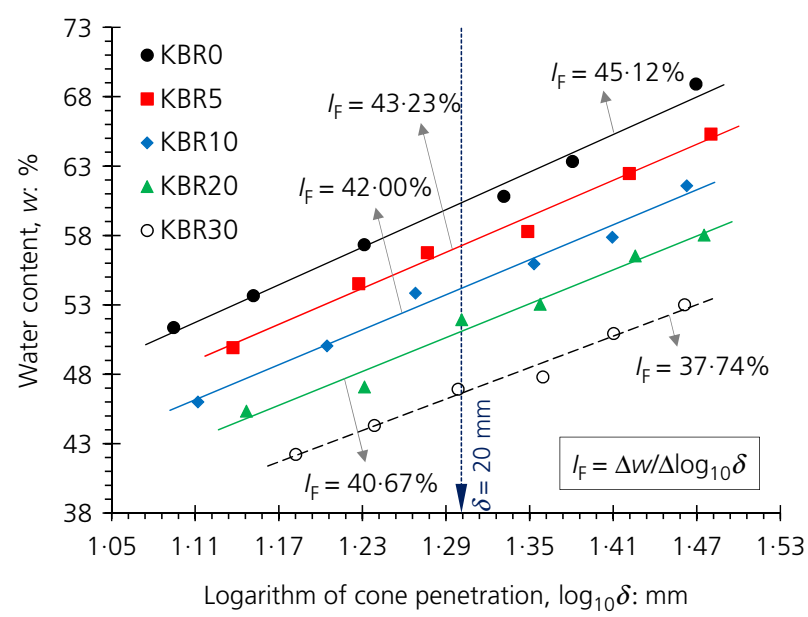

(c)

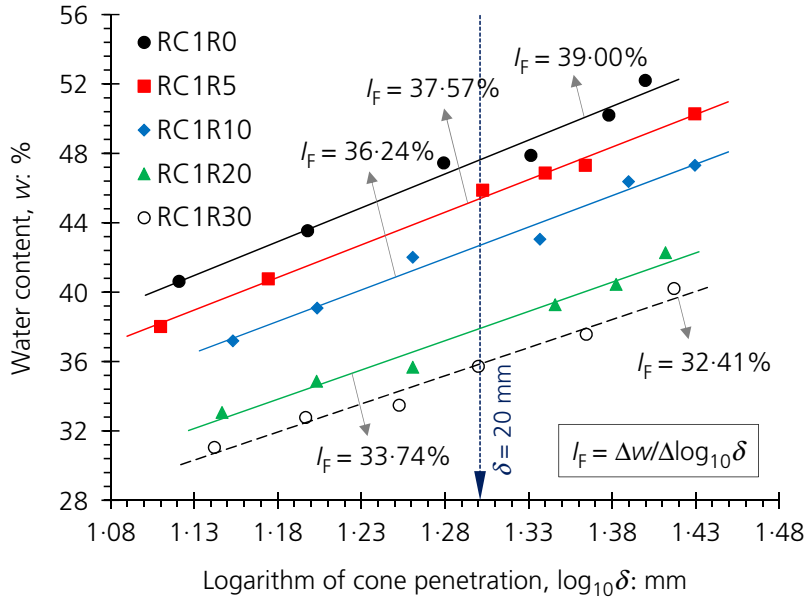

(b)

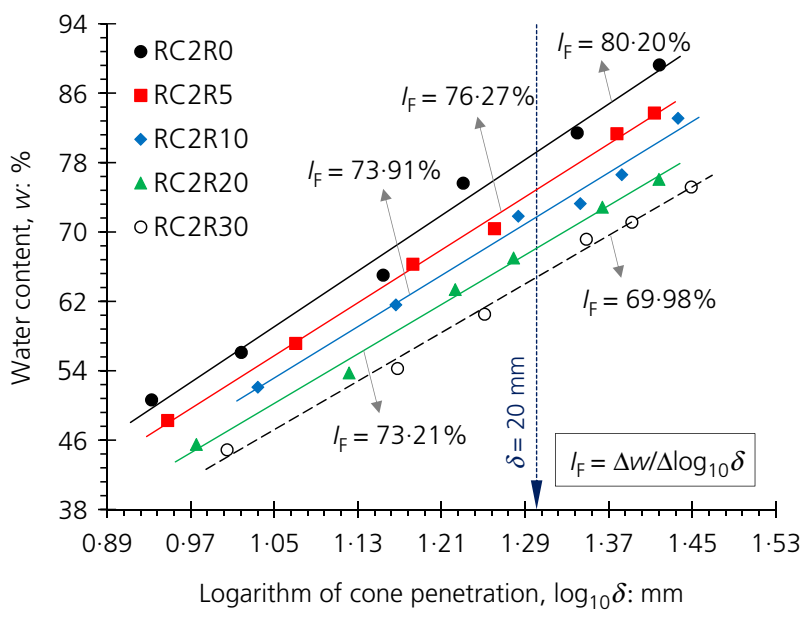

(d)

Figure 3. Flow curves for the virgin clays and various GRC blends: (a) soil K; (b) soil RC1; (c) soil KB; (d) soil RC2

the $\mathrm{CH}$ soils (i.e. soils $\mathrm{KB}$ and $\mathrm{RC} 2$ ) exhibiting a greater tendency for reduction compared with the CI soils (i.e. soils $\mathrm{K}$ and $\mathrm{RC} 1$ ). In terms of the liquid limit, for instance, the soils $\mathrm{KB}$ and $\mathrm{RC} 2$ resulted in $\Delta w_{\mathrm{L}} / \Delta R_{\mathrm{c}}=-0.425$ and $-0 \cdot 456$, respectively. For the soils $\mathrm{K}$ and $\mathrm{RC} 1$, however, these values dropped to $-0 \cdot 347$ and $-0 \cdot 401$, respectively.

Figure 5 illustrates the location of the tested mix designs on Casagrande's plasticity chart (Figure 5(a): soils K and KB; Figure 5(b): soils RC1 and RC2). For a given type of soil, the variations of $I_{\mathrm{P}}$ against $w_{\mathrm{L}}$ followed a linear path (see the arrowed lines labelled ' 1 ' and ' 2 ' in Figure 5), with relatively lower slopes (i.e. $\Delta I_{\mathrm{P}} / \Delta w_{\mathrm{L}}$ ) compared with that of the 'A' and ' $U$ ' lines of the plasticity chart. Furthermore, the value of $\Delta I_{\mathrm{P}} / \Delta w_{\mathrm{L}}$ was dependent on the type of soil, with the $\mathrm{CH}$ soils (i.e. soils $\mathrm{KB}$ and $\mathrm{RC} 2$ ) exhibiting greater slopes compared with that of the $\mathrm{CI}$ soils (i.e. soils $\mathrm{K}$ and $\mathrm{RC} 1$ ). The soils $\mathrm{KB}$ and $\mathrm{RC} 2$ resulted in $\Delta I_{\mathrm{P}} / \Delta w_{\mathrm{L}}=0.383$ and 0.517 , respectively. For the soils $\mathrm{K}$ and $\mathrm{RC} 1$, however, these values changed to
$0 \cdot 329$ and $0 \cdot 395$, respectively. For a given type of soil, an increase in rubber content relocated the soil towards lower plasticity regions (follow the arrowed lines ' 1 ' and ' 2 ' in Figure 5), while mainly maintaining the original USCS classification observed for the virgin soil. Two exceptions, however, were the soils $\mathrm{K}$ and $\mathrm{KB}$ at $R_{\mathrm{c}}=30 \%$, which transitioned from the $\mathrm{CI}$ and $\mathrm{CH}$ categories to $\mathrm{CL}$ ('clay with low plasticity') and CI categories, respectively (see KR30 and KBR30 in Figure 5(a)).

The consistency limits, the liquid limit in particular, can be employed to infer the development of soil fabric (Kim and Palomino, 2009; Soltani et al., 2018b; Wroth and Wood, 1978). A decrease in the liquid limit, as is the case with GRC blends (see Figure 4), implies that a face-to-face aggregated (or dispersed) fabric dominates the GRC matrix (Mitchell and Soga, 2005). As opposed to the edge-to-face flocculated fabric, a face-to-face aggregated fabric offers less resistance to shear (or cone penetration), which in turn leads to lower liquid limits 


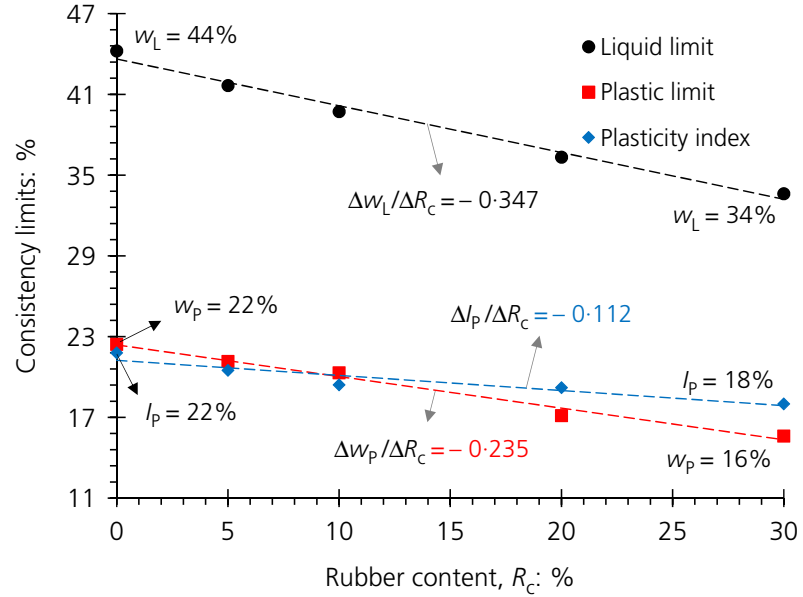

(a)

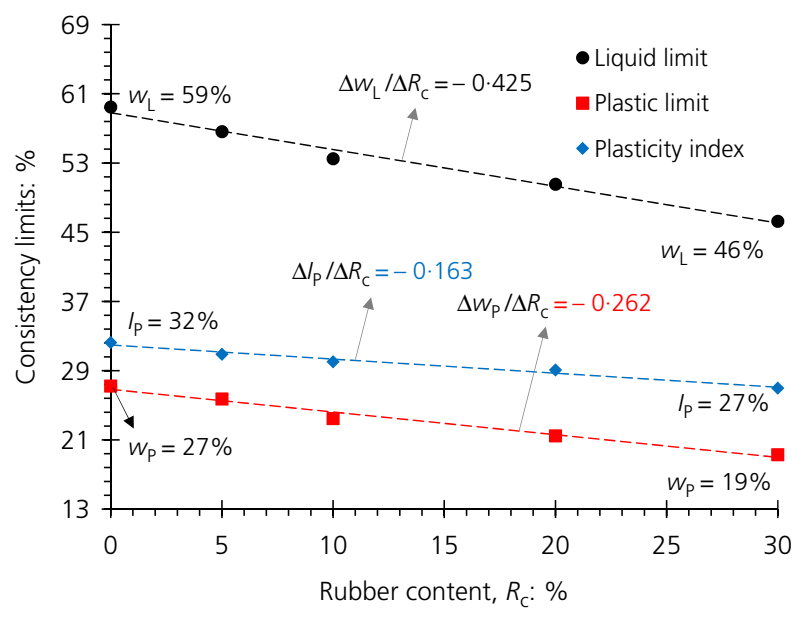

(c)

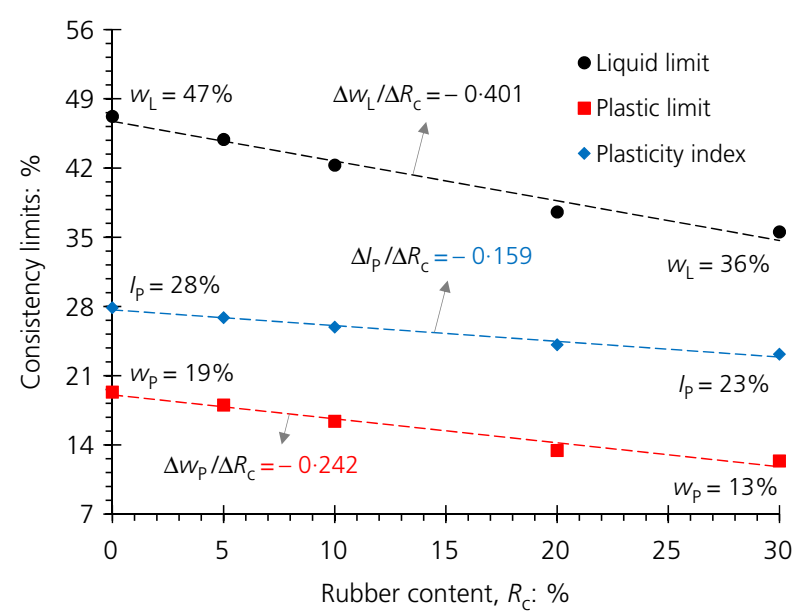

(b)

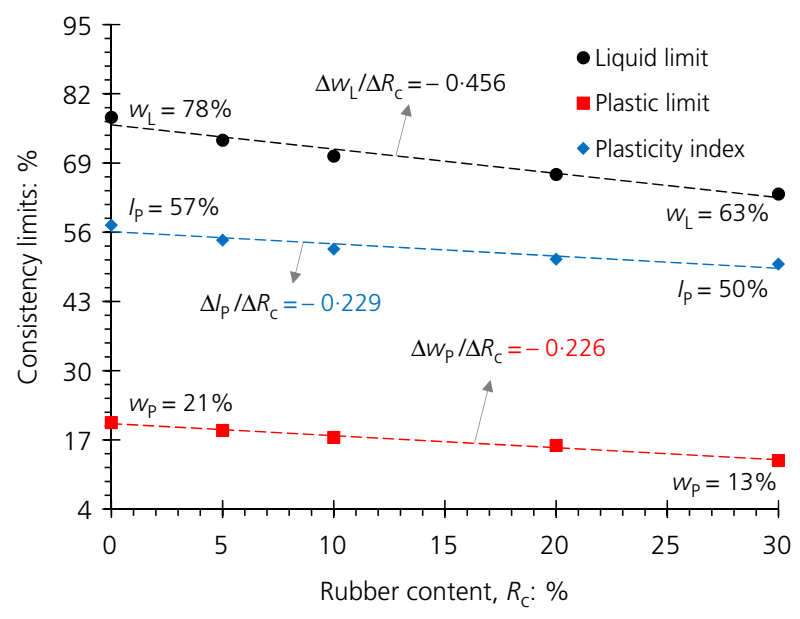

(d)

Figure 4. Variations of the consistency limits against rubber content for the virgin clays and various GRC blends: (a) soil K; (b) soil RC1; (c) soil KB; (d) soil RC2

(i.e. the $20 \mathrm{~mm}$ cone penetration is achieved at lower water contents). Moreover, reduction in the consistency limits as a result of GR inclusion can be attributed to the lower specific surface area and water adsorption capacity of the rubber particles compared with the soil grains (Cetin et al., 2006; Srivastava et al., 2014; Trouzine et al., 2012). The consistency limits are primarily a function of the soil's clay (or fines) content, with higher clay contents exhibiting higher liquid and plastic limits. Quite clearly, an increase in rubber content substitutes a larger portion of the clay content with non-plastic hydrophobic rubber particles, thus leading to a further decrease of the consistency limits.

\subsection{Effect of GR on compaction characteristics}

Standard Proctor compaction curves, along with corresponding specific gravities (obtained as per Equation 1) and zero-air voids ( $\mathrm{ZAV})$ saturation lines, for the virgin clays and various GRC blends prepared with soils $\mathrm{K}, \mathrm{RC} 1, \mathrm{~KB}$ and $\mathrm{RC} 2$ are provided in Figures 6(a), 6(b), 6(c) and 6(d), respectively. For a given type of soil, the higher the rubber content the lower the average specific gravity $G_{\text {sm }}$, following a monotonic decreasing trend. As a result of GR inclusion, the compaction locus exhibited a major downward-leftward translation over the $\gamma_{\mathrm{d}}-w$ space $\left(\gamma_{\mathrm{d}}\right.$ is the dry unit weight and $w$ is the water content), indicating a significant reduction in both the optimum water content $w_{\text {opt }}$ and the maximum dry unit weight $\gamma_{\text {dmax }}$. Such results foster the use of GR as a viable lightweight alternative for common quarry materials such as sand. For a given type of soil, the peak (or optimum) points followed a linear decreasing trend with increase in rubber content $R_{\mathrm{c}}$ (follow the arrowed lines in Figure 6), thereby signifying the existence of a linear relationship for both $w_{\text {opt }}$ and $\gamma_{\text {dmax }}$ with $R_{\text {c. }}$ The linear tendency for reduction is in compliance with that reported in most of the existing literature sources (e.g. Cabalar et al., 2014; Signes et al., 2016; Yadav and Tiwari, 2017a). 


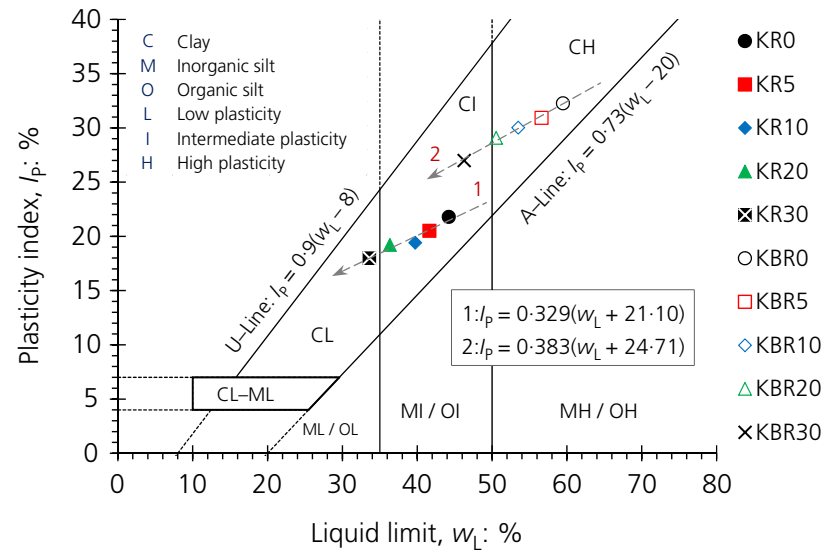

(a)

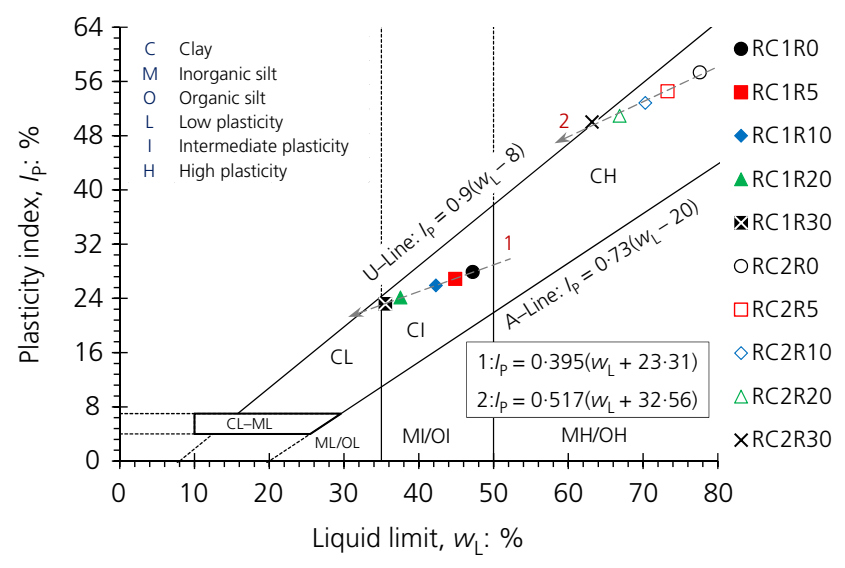

(b)

Figure 5. Location of the tested mix designs on Casagrande's plasticity chart: (a) soils $\mathrm{K}$ and $\mathrm{KB}$; (b) soils RC1 and RC2

Figures 7(a) and 7(b) illustrate the variations of the compaction characteristics - namely, $w_{\mathrm{opt}}$ and $\gamma_{\mathrm{dmax}}-$ against $R_{\mathrm{c}}$ for the tested mix designs, respectively. The higher the rubber content the lower the compaction characteristics, following a linear monotonic decreasing trend. The virgin clay $\mathrm{KB}$, for instance, resulted in $w_{\text {opt }}=25 \%\left(\gamma_{\mathrm{dmax}}=14.61 \mathrm{kN} / \mathrm{m}^{3}\right)$, while the inclusion of 5, 10, 20 and 30\% GR resulted in $w_{\mathrm{opt}}=24 \%$ $\left(\gamma_{\text {dmax }}=14.27 \mathrm{kN} / \mathrm{m}^{3}\right), \quad 22 \% \quad\left(\gamma_{\text {dmax }}=14 \cdot 16 \mathrm{kN} / \mathrm{m}^{3}\right), \quad 21 \%$ $\left(\gamma_{\mathrm{dmax}}=13.71 \mathrm{kN} / \mathrm{m}^{3}\right)$ and $18 \%\left(\gamma_{\mathrm{dmax}}=13.17 \mathrm{kN} / \mathrm{m}^{3}\right)$, respectively. Similarly to the consistency limits (see Figure 4), the rate of decrease in $w_{\text {opt }}$ with respect to $R_{\mathrm{c}}$ - represented by the slope of a typical linear trend line fitted through a desired $w_{\text {opt }}-R_{\mathrm{c}}$ dataset (i.e. $\Delta w_{\text {opt }} / \Delta R_{\mathrm{c}}$ ) - was observed to be dependent on the type of soil, with the $\mathrm{CH}$ soils (i.e. soils $\mathrm{KB}$ and $\mathrm{RC} 2$ ) exhibiting a greater tendency for reduction compared with the $\mathrm{CI}$ soils (i.e. soils $\mathrm{K}$ and $\mathrm{RC} 1$ ). As demonstrated in Figure 7(a), the soils $\mathrm{KB}$ and $\mathrm{RC} 2$ resulted in $\Delta w_{\text {opt }} / \Delta R_{\mathrm{c}}=-0 \cdot 224$ and $-0 \cdot 196$, respectively. For the soils $\mathrm{K}$ and $\mathrm{RC} 1$, however, these values dropped to $-0 \cdot 160$ and $-0 \cdot 114$, respectively. On the contrary, as depicted in Figure 7(b), an opposite effect can be concluded for $\gamma_{\mathrm{dmax}}$, as
$\Delta \gamma_{\mathrm{dmax}} / \Delta R_{\mathrm{c}}$ was observed to be slightly higher for the CI soils compared with that of the $\mathrm{CH}$ soils (i.e. $\Delta \gamma_{\mathrm{dmax}} / \Delta R_{\mathrm{c}}=-0.052$, $-0.059,-0.046$ and -0.043 for soils $\mathrm{K}, \mathrm{RC} 1, \mathrm{~KB}$ and $\mathrm{RC} 2$, respectively).

Reduction in the compaction characteristics as a result of GR inclusion can be attributed to the lower specific gravity and hydrophobic nature of the rubber particles compared with the soil grains (Cabalar et al., 2014; Özkul and Baykal, 2007; Signes et al., 2016). Similarly to the consistency limits, the optimum water content is primarily a function of the soil's clay/fines content, with higher clay contents exhibiting a higher optimum water content. Consequently, an increase in rubber content substitutes a larger portion of the clay content with hydrophobic rubber particles, which in turn leads to a further decrease of the optimum water content. The maximum dry unit weight is proportional to the composite's specific gravity, with higher specific gravities yielding a higher maximum dry unit weight. As such, an increase in rubber content substitutes a larger portion of the soil (with a high specific gravity) with low-specific-gravity rubber particles, which leads to a further decrease of the composite's average specific gravity (see $G_{\text {sm }}$ values in Figure 6) and hence its maximum dry unit weight. Moreover, the elastic (or rebound) response of GR to dynamic energy during compaction may potentially reduce the compaction efficiency, and thus contribute to a lower maximum dry unit weight (Yadav and Tiwari, 2017b).

\subsection{Compaction characteristics as a function of consistency limits}

The conventional compaction test, although simple in terms of procedure, has been widely regarded as a laborious and timeconsuming task (Sridharan and Sivapullaiah, 2005). Although numerous attempts have been made in the past to correlate the compaction characteristics with the consistency limits, such correlative models have not yet been extended to GRC blends (or other similar geomaterials). As such, the present section will be devoted to the development of practical models capable of predicting the compaction characteristics of GRC blends as a function of the consistency limits.

Figure 8 illustrates the variations of the optimum water content $w_{\text {opt }}$ (data presented in Figure 7(a)) against the consistency limits - namely, the liquid limit $w_{\mathrm{L}}$, plastic limit $w_{\mathrm{P}}$ and plasticity index $I_{\mathrm{P}}$ (data presented in Figures 4(a)-4(d)), for the tested mix designs (Figure 8(a): $w_{\mathrm{opt}}-w_{\mathrm{L}}$; Figure 8(b): $w_{\mathrm{opt}}-w_{\mathrm{P}}$; and Figure 8(c): $\left.w_{\mathrm{opt}}-I_{\mathrm{P}}\right)$. As depicted in Figures 8(a) and 8(c), $w_{\mathrm{L}}$ and $I_{\mathrm{P}}$ both exhibit weak correlations with $w_{\mathrm{opt}}$, and thus are deemed as unsuitable for model development. The ineptness of the liquid limit in predicting the compaction characteristics of natural fine-grained soils was first recognised by Sridharan and Nagaraj (2005), and was attributed to the fact that soils having the same liquid limit (but different plasticity characteristics) often exhibit different compaction behaviour. On the contrary, $w_{\mathrm{P}}$ exhibits a rather strong correlation 


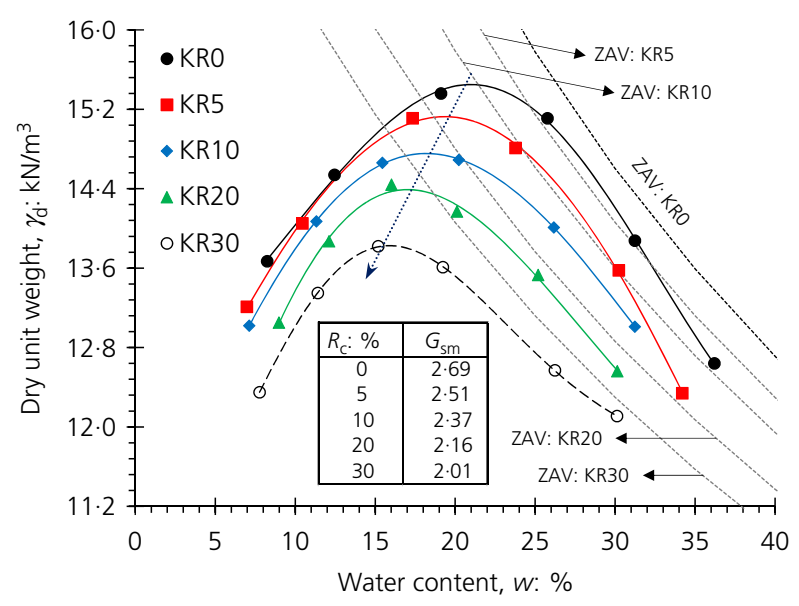

(a)

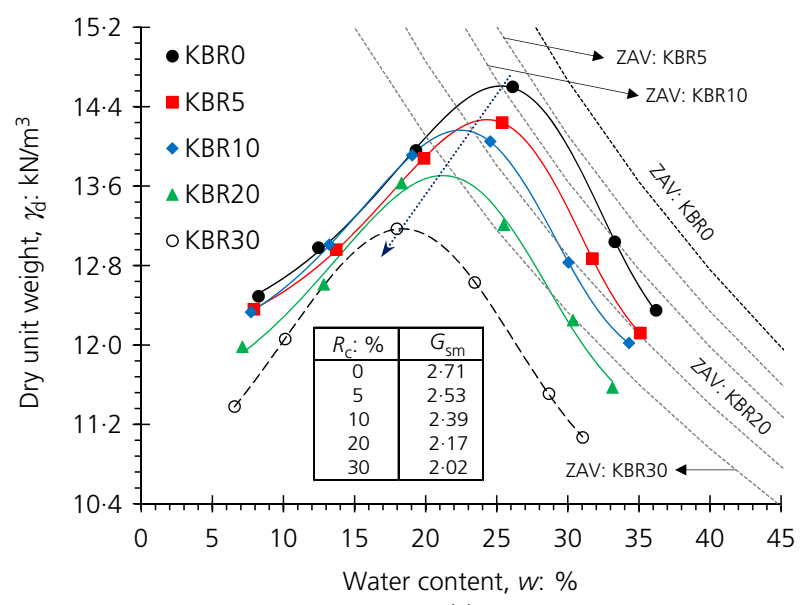

(c)

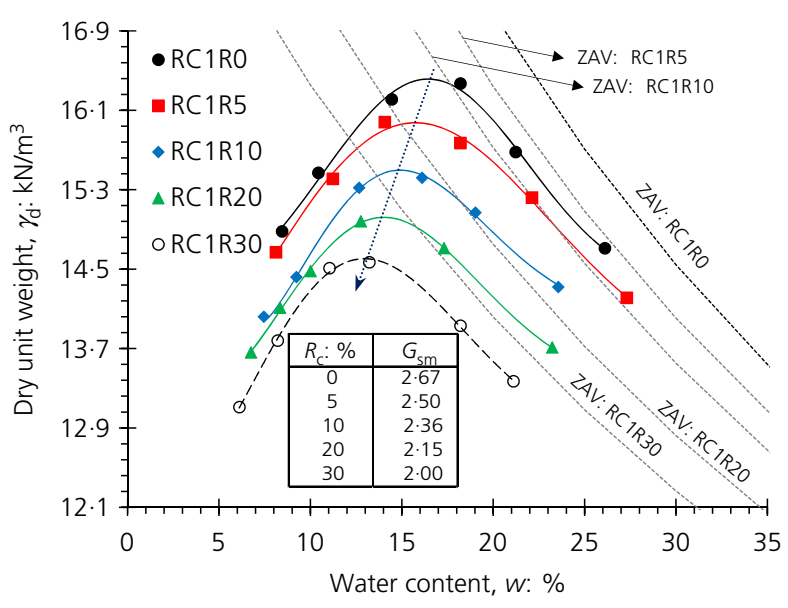

(b)

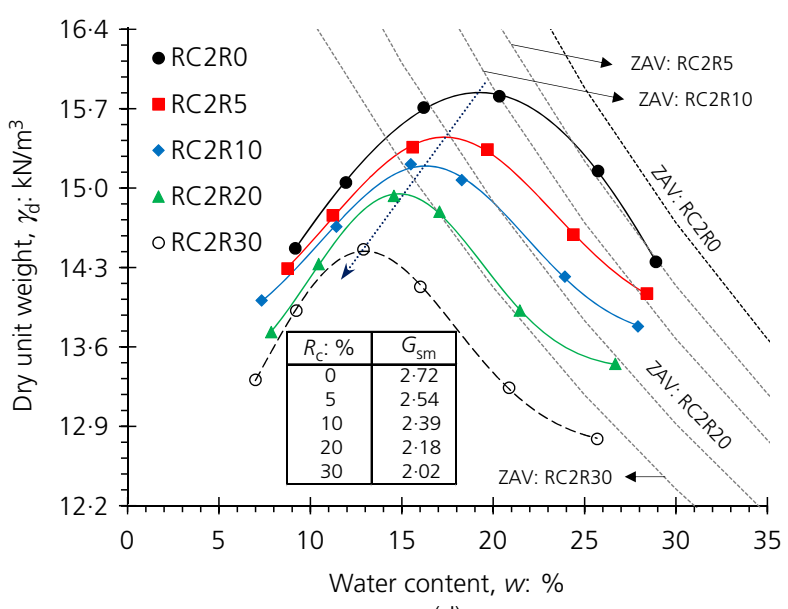

(d)

Figure 6. Standard Proctor compaction curves for the virgin clays and various GRC blends: (a) soil K; (b) soil RC1; (c) soil KB; (d) soil RC2

(with $R^{2}=0 \cdot 950$ ) in the form of a single-coefficient linear function with $w_{\text {opt }}$ (see Figure $8($ b)), which can be given as

4. $w_{\mathrm{opt}}=0.941 w_{\mathrm{P}}$

Although some scatter can be observed with respect to Equation 4, all data points lie between the upper and lower $95 \%$ prediction bands, thus indicating no particular outliers associated with the predictions (see Figure 8(b)). Interestingly, the proposed model given in Equation 4 complies well with those suggested in the literature for natural soils (but with a slightly different coefficient compared to 0.941) - for example, $w_{\text {opt }}=0 \cdot 92 w_{\mathrm{P}}$ (Sridharan and Nagaraj, 2005) and $w_{\text {opt }}=0 \cdot 84 w_{\mathrm{P}}$ (Nagaraj et al., 2015).

It is well accepted that the maximum dry unit weight $\gamma_{\mathrm{dmax}}$ is proportional to the dry unit weight at the plastic limit water content with a presumptive saturation degree of $100 \%$ (Gurtug and Sridharan, 2002, 2004; Gurtug et al., 2018; Pillai and
Vinod, 2016). Making use of basic volume-mass relations, the dry unit weight at plastic limit $\gamma_{\mathrm{dP}}$ can be expressed as

5. $\gamma_{\mathrm{dP}}=\frac{G_{\mathrm{sm}} \gamma_{\mathrm{w}}}{1+G_{\mathrm{sm}} w_{\mathrm{P}}}$

where $G_{\mathrm{sm}}$ is the average specific gravity of GRC blends (values presented in Figure 6); and $\gamma_{\mathrm{w}}$ is the unit weight of water $\left(=9 \cdot 81 \mathrm{kN} / \mathrm{m}^{3}\right)$.

The variations of $\gamma_{\text {dmax }}$ (data presented in Figure $7(b)$ ) were plotted against $\gamma_{\mathrm{dP}}$ (obtained as per Equation 5) for the various mix designs, and the results are provided in Figure 9. A similar correlation to that observed between $w_{\mathrm{opt}}$ and $w_{\mathrm{P}}$ also exists between $\gamma_{\mathrm{dmax}}$ and $\gamma_{\mathrm{dP}}$ (with $R^{2}=0.942$ ), which can be expressed as

6. $\gamma_{\mathrm{dmax}}=0.932 \gamma_{\mathrm{dP}}=\frac{0.932 G_{\mathrm{sm}} \gamma_{\mathrm{w}}}{1+G_{\mathrm{sm}} w_{\mathrm{P}}}$ 


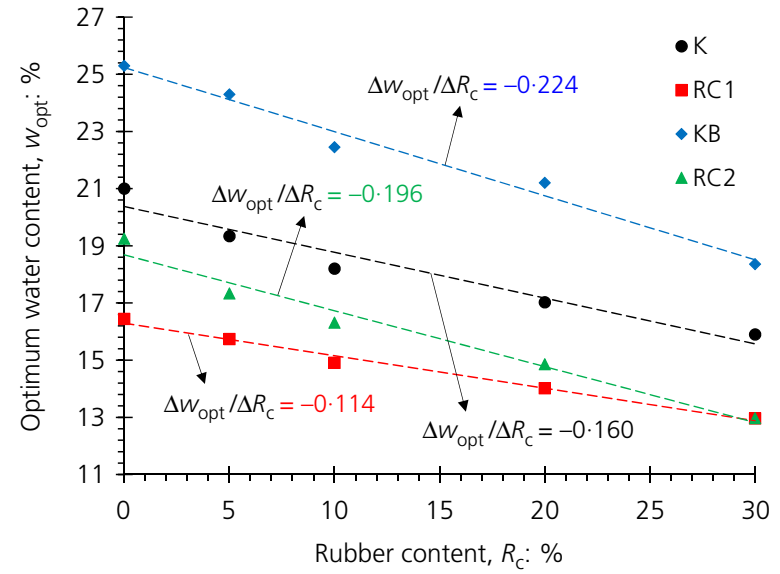

(a)



(b)

Figure 7. Variations of the compaction characteristics plotted against rubber content for the tested mix designs: (a) optimum water content; (b) maximum dry unit weight

As depicted in Figure 9, all data points with respect to Equation 6 position themselves between the upper and lower 95\% prediction bands, thereby suggesting no particular outliers associated with the predictions. Previous studies such as Gurtug and Sridharan (2002) have suggested a different coefficient of 0.98 for natural fine-grained soils - that is, $\gamma_{\mathrm{dmax}}=0.98 \gamma_{\mathrm{dP}}$, which is slightly higher compared to the 0.932 obtained in the present study. This may be attributed to the lower average specific gravity of GRC blends compared with that of the virgin clays, which in turn gives rise to lower $\gamma_{\mathrm{dP}}$ values.

Figures 10(a) and 10(b) illustrate the variations of both the actual and predicted $w_{\text {opt }}$ and $\gamma_{\mathrm{dmax}}$ data against rubber content $R_{\mathrm{c}}$ for the tested mix designs, respectively. The proposed models - that is, Equation 4 for $w_{\text {opt }}$ and Equation 6 for $\gamma_{\text {dmax }}$, comply well with experimental observations, as evident with the clustering of actual and predicted data in the figures.

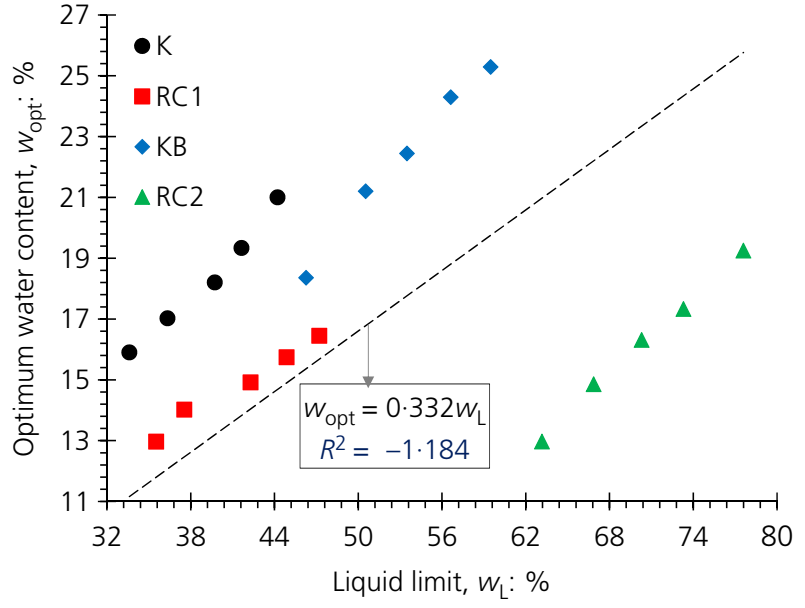

(a)



(b)

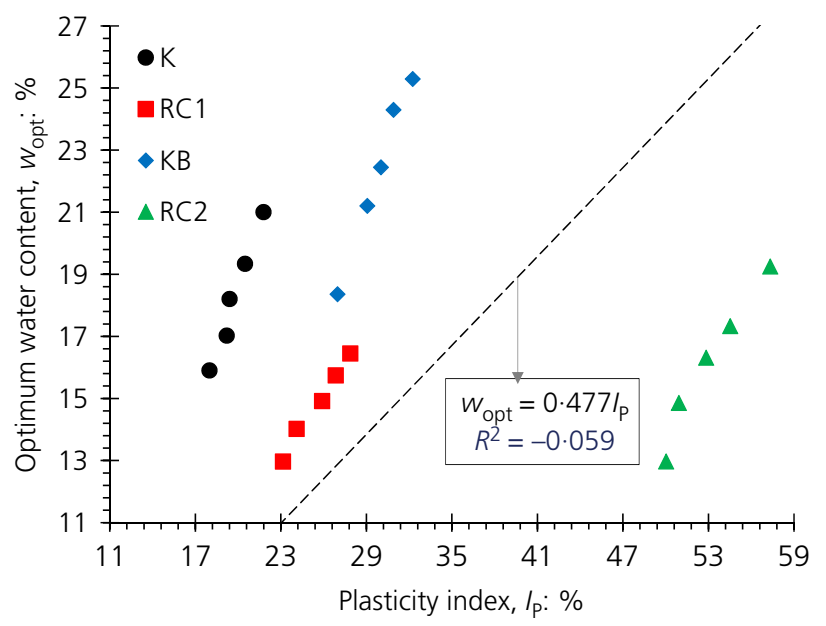

(c)

Figure 8. Variations of the optimum water content plotted against the consistency limits for the tested mix designs: (a) liquid limit; (b) plastic limit; (c) plasticity index 


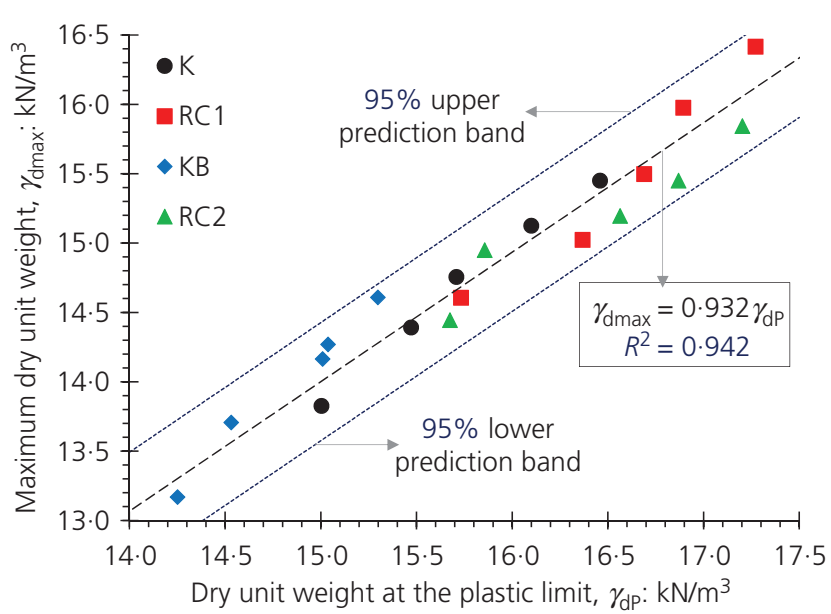

Figure 9. Variations of the maximum dry unit weight plotted against the dry unit weight at the plastic limit for the tested mix designs

Most of the predicted values perfectly overlap with their actual counterparts, thus signifying an excellent capacity to simulate the compaction characteristics of GRC blends by means of the plastic limit. In general, a reliable empirical model can be characterised as one that maintains a perfect balance between the apparent correlation and the exhibited error (or accuracy). The former is taken into consideration by means of the coefficient of determination $R^{2}$, with values closer to unity implying a stronger correlation. The latter is commonly examined by means of the normalised root-mean-square error (NRMSE) (in \%) and the mean absolute percentage error (MAPE) (in \%), with values closer to zero representing a higher degree of accuracy (Soltani et al., 2018d). The NRMSE and MAPE indices can be obtained by the following

7. $\mathrm{NRMSE}=\frac{\sqrt{(1 / N) \sum_{i=1}^{N}\left(y_{\mathrm{m} i}-y_{\mathrm{a} i}\right)^{2}}}{y_{\mathrm{a} \max }-y_{\mathrm{a} \min }} \times 100$

8. $\mathrm{MAPE}=\frac{1}{N} \sum_{i=1}^{N}\left|\frac{y_{\mathrm{m} i}-y_{\mathrm{a} i}}{y_{\mathrm{a} i}}\right| \times 100$

where $y_{\mathrm{m}}$ is the predicted value of the dependent variable $y$ $\left(=w_{\mathrm{opt}}\right.$ or $\left.\gamma_{\mathrm{dmax}}\right) ; y_{\mathrm{a}}$ is the actual value of the dependent variable $y$ (data presented in Figure 7); $y_{\mathrm{a} \max }$ is the maximum value of $y_{\mathrm{a}}$ data; $y_{\mathrm{amin}}$ is the minimum value of $y_{\mathrm{a}}$ data; $i$ is the index of summation; and $N$ is the number of data points used for model development $(=20$, consisting of four virgin clays and 16 GRC blends).

The suggested models for $w_{\text {opt }}$ (Equation 4) and $\gamma_{\text {dmax }}$ (Equation 6), respectively, resulted in $R^{2}$ values of 0.950 and 0.942 , thus implying that approximately $95 \%$ of the variations in experimental observations are captured and further explained by the proposed correlative models. The NRMSE and MAPE indices were, respectively, found to be $6.73 \%$ and $4.09 \%$ for $w_{\text {opt }}$, and $6.05 \%$ and $1 \cdot 18 \%$ for $\gamma_{\mathrm{dmax}}$, thereby indicating an average offset of approximately $5 \%$ associated with the predictive capacity of the proposed models.

As demonstrated in Figures 4(a)-4(d), the plastic limit $w_{\mathrm{P}}$ exhibited a linear relationship with rubber content $R_{\mathrm{c}}$. For a given type of soil, it is therefore possible to write the following

9. $w_{\mathrm{P}}=w_{\mathrm{Po}}-\eta R_{\mathrm{c}}$

where $w_{\mathrm{Po}}$ is the plastic limit for the virgin clay (\%) and $\eta$ is the coefficient of plastic limit reduction (dimensionless).

The coefficient of plastic limit reduction $\eta$ can be estimated by one plastic limit measurement for an arbitrary GRC blend. The choice of rubber content for the GRC blend would be arbitrary. From a statistical perspective, however, a median rubber content, taken as half the predefined maximum rubber content, is expected to provide a more reliable estimate of $\eta$ (Mirzababaei et al., 2018). For the present study where $R_{\mathrm{c}} \leq 30 \%$, a median rubber content would be $15 \%$. Consider the following designations

$R_{\mathrm{c}}^{\mathrm{M}}=$ an arbitrary median rubber content

- $w_{\mathrm{P}}^{\mathrm{M}}=$ plastic limit corresponding to an arbitrary median rubber content $R_{\mathrm{c}}^{\mathrm{M}}$ (obtained in accordance with the flow index method, as outlined in Section 3.1).

Therefore, the following can be derived for $\eta$

10. $\eta=\frac{w_{\mathrm{Po}}-w_{\mathrm{P}}^{\mathrm{M}}}{R_{\mathrm{c}}^{\mathrm{M}}}$

By substituting the recent Equation 9 into Equation 4, it is possible to derive the following for $w_{\mathrm{opt}}$

11. $w_{\mathrm{opt}}=0.941\left(w_{\mathrm{Po}}-\eta R_{\mathrm{c}}\right)$

Similarly, by substituting Equation 9 into Equation $6, \gamma_{\text {dmax }}$ can expressed as

12. $\gamma_{\mathrm{dmax}}=0.932 \gamma_{\mathrm{dP}}=\frac{0.932 G_{\mathrm{sm}} \gamma_{\mathrm{w}}}{1+G_{\mathrm{sm}}\left(w_{\mathrm{Po}}-\eta R_{\mathrm{c}}\right)}$

Although the original models given in Equations 4 and 6 offer a fairly practical procedure towards predicting the compaction characteristics of GRC blends without the hurdles of 

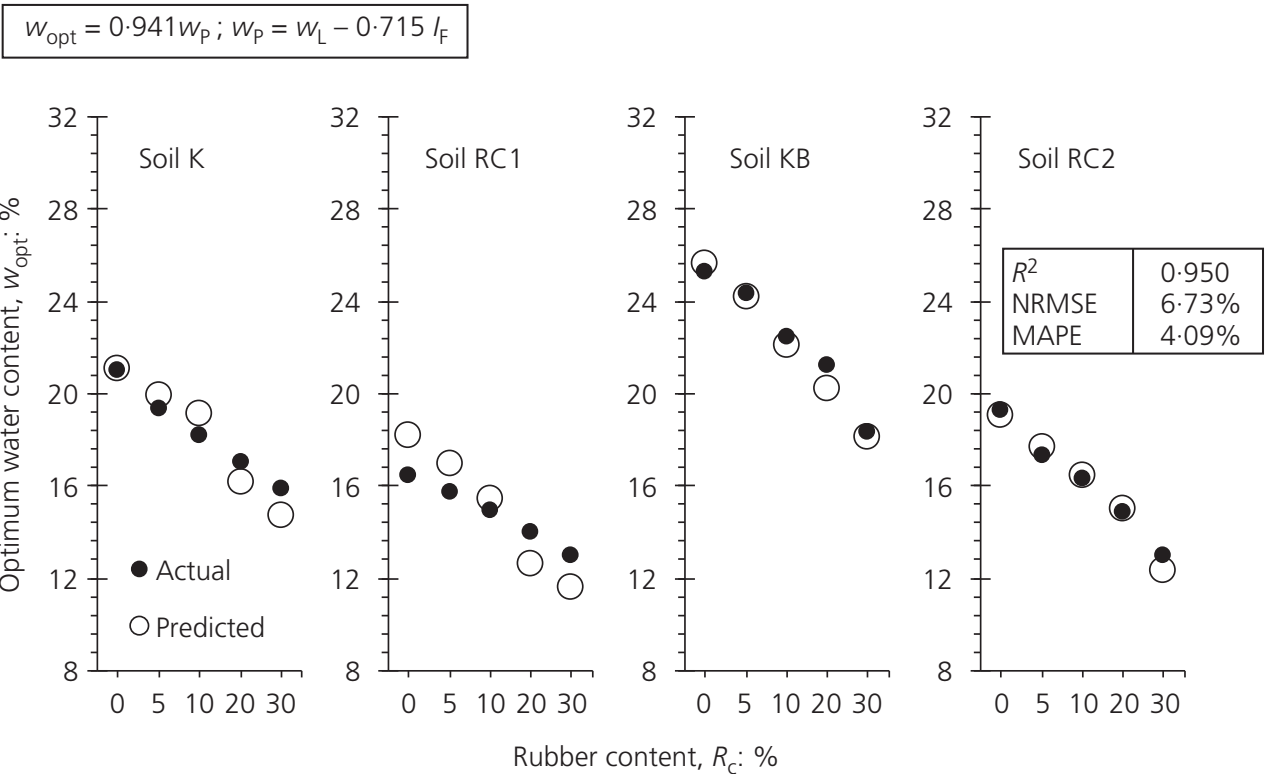

(a)
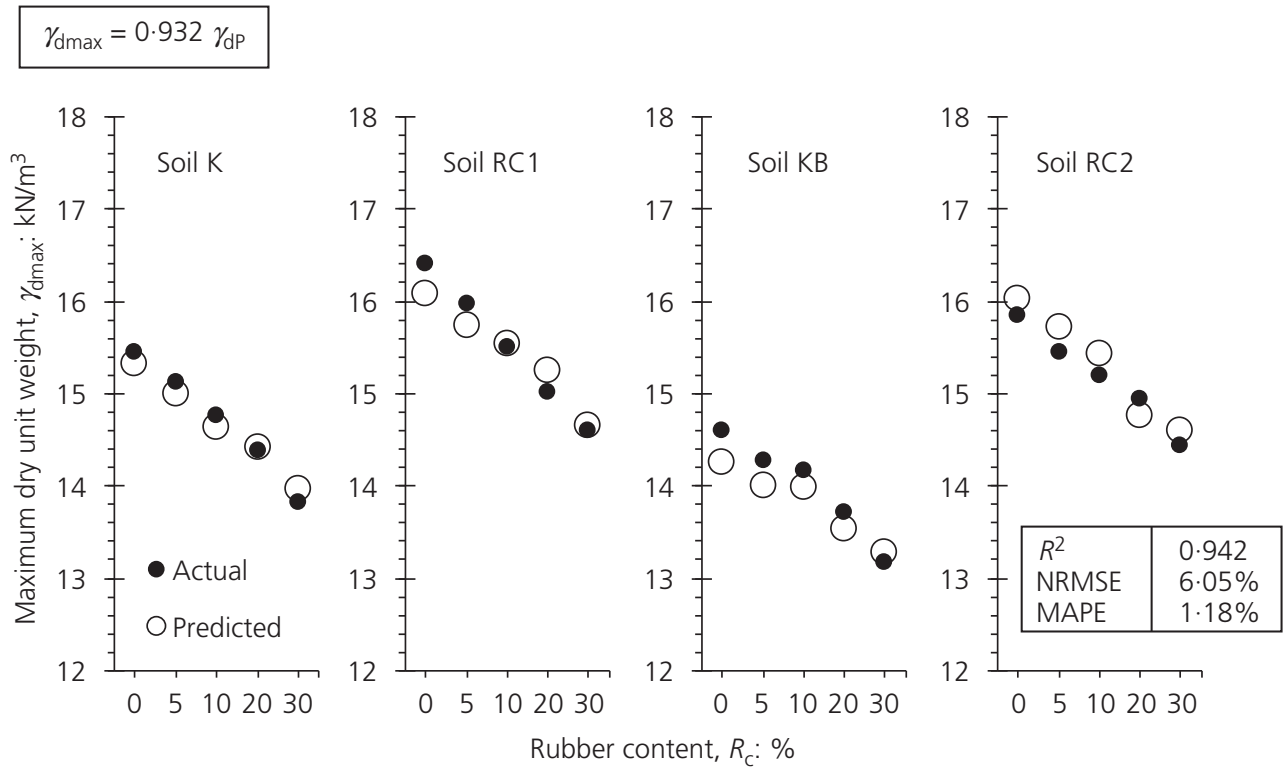

(b)

Figure 10. Variations of both the actual and predicted compaction data plotted against rubber content for the tested mix designs: (a) optimum water content (predicted by Equation 4); (b) maximum dry unit weight (predicted by Equation 6)

conducting the conventional compaction test, the procedure may still be somewhat time-consuming, since a separate plastic limit measurement is to be carried out for each desired rubber content. The newly developed models given in Equations 11 and 12, however, suggest a more practical approach, one that requires only two plastic limit measurements (i.e. $w_{\text {Po }}$, which is the plastic limit for the virgin clay; and $w_{\mathrm{P}}^{\mathrm{M}}$, which is the plastic limit corresponding to an arbitrary median rubber content $R_{\mathrm{c}}^{\mathrm{M}}$ ) to arrive at an estimate of the compaction characteristics over a wide range of desired rubber contents. Similar correlative models may also be developed for different compaction energy levels, and thus to arrive at a unified framework capable of predicting the compaction characteristics of GRC blends for any desired rubber content and/or rational compaction energy level.

\section{Conclusions}

The following conclusions can be drawn from this study.

As a result of GR inclusion, the consistency limits - namely, the liquid limit $w_{\mathrm{L}}$, plastic limit $w_{\mathrm{P}}$ $\left(w_{\mathrm{P}}=w_{\mathrm{L}}-0 \cdot 715 I_{\mathrm{F}}\right.$, where $I_{\mathrm{F}}=$ flow index $)$ and plasticity 
index $I_{\mathrm{P}}\left(I_{\mathrm{P}}=0 \cdot 715 I_{\mathrm{F}}\right)$, exhibited a linear monotonic decreasing trend with increase in rubber content.

The rate of decrease in $w_{\mathrm{L}}, w_{\mathrm{B}} I_{\mathrm{F}}$ and $I_{\mathrm{P}}$ was dependent on the type of soil, with the $\mathrm{CH}$ soils (high-plasticity clays) exhibiting a greater tendency for reduction compared with that of the CI soils (intermediate-plasticity clays).

- As a result of GR inclusion, the compaction characteristics - that is, the optimum water content $w_{\mathrm{opt}}$ and the maximum dry unit weight $\gamma_{\text {dmax }}$ - exhibited a linear monotonic decreasing trend with increase in rubber content. Similarly to the consistency limits, the rate of decrease in $w_{\text {opt }}$ was dependent on the type of soil, with the $\mathrm{CH}$ soils exhibiting a greater tendency for reduction. The rate of decrease in $\gamma_{\mathrm{dmax}}$, however, was less influenced by the type of soil. Such results foster the use of GRC blends as a viable lightweight material for the construction of sustainable earth fills, thus serving a variety of infrastructure needs - for example, road/railway embankments, retaining walls and bridge abutments.

- The compaction characteristics were strongly correlated with the plastic limit. In this case, simple correlative models in the form of $w_{\mathrm{opt}}=0.941 w_{\mathrm{P}}$ and $\gamma_{\mathrm{dmax}}=0.932 \gamma_{\mathrm{dP}}$ $\left(\gamma_{\mathrm{dP}}\right.$ is the dry unit weight at plastic limit water content with a presumptive saturation degree of $100 \%$ ) were obtained for the optimum water content and the maximum dry unit weight, respectively. The predictive capacity of the proposed models was examined and further validated by statistical techniques. The proposed correlative models offer a practical procedure towards predicting the compaction characteristics of GRC blends without the hurdles of conducting the conventional compaction test, and hence can be implemented in practice for preliminary assessments.

\section{Acknowledgement}

This research was funded by the Australian Research Council (ARC) by way of project no. DP140103004; this support is gratefully acknowledged.

\section{REFERENCES}

ACl (American Concrete Institute) (2013) ACI 229: Report on controlled low-strength materials. American Concrete Institute, Farmington Hills, MI, USA.

Al-Amoudi OSB, Al-Homidy AA, Maslehuddin M and Saleh TA (2017) Method and mechanisms of soil stabilisation using electric arc furnace dust. Scientific Reports 7: 46676, https://doi.org/ $10.1038 /$ srep46676.

Alazigha DP, Indraratna B, Vinod JS and Ezeajugh LE (2016) The swelling behaviour of lignosulfonate-treated expansive soil. Proceedings of the Institution of Civil Engineers - Ground Improvement 169(3): 182-193, https://doi.org/10.1680/jgrim.15.00002.

Al-Tabbaa A, Blackwell O and Porter SA (1997) An investigation into the geotechnical properties of soil-tyre mixtures. Environmental Technology 18(8): 855-860, https://doi.org/10.1080/ 09593331808616605 .
Arulrajah A, Mohammadinia A, D'Amico A and Horpibulsuk S (2017) Effect of lime kiln dust as an alternative binder in the stabilisation of construction and demolition materials. Construction and Building Materials 152: 999-1007, https://doi.org/10.1016/ j.conbuildmat.2017.07.070.

ASTM (2007) D422-63(2007)e2: Standard test method for particle-size analysis of soils. ASTM International, West Conshohocken, PA, USA.

ASTM (2011) D2487-11: Standard practice for classification of soils for engineering purposes (Unified Soil Classification System). ASTM International, West Conshohocken, PA, USA.

ASTM (2012) D698-12e2: Standard test methods for laboratory compaction characteristics of soil using standard effort $\left(12,400 \mathrm{ft}-\mathrm{lbf} / \mathrm{ft}^{3}\left(600 \mathrm{kN}-\mathrm{m} / \mathrm{m}^{3}\right)\right)$. ASTM International, West Conshohocken, PA, USA.

ASTM (2014) D854-14: Standard test methods for specific gravity of soil solids by water pycnometer. ASTM International, West Conshohocken, PA, USA.

Blotz LR, Benson CH and Boutwell GP (1998) Estimating optimum water content and maximum dry unit weight for compacted clays. Journal of Geotechnical and Geoenvironmental Engineering 124(9): 907-912, https://doi.org/10.1061/(asce)1090-0241(1998) 124:9(907).

Cabalar AF, Karabash Z and Mustafa WS (2014) Stabilising a clay using tyre buffings and lime. Road Materials and Pavement Design 15(4): 872-891, https://doi.org/10.1080/14680629.2014.939697.

Cetin H, Fener M and Gunaydin O (2006) Geotechnical properties of tire-cohesive clayey soil mixtures as a fill material. Engineering Geology 88(1-2): 110-120, https://doi.org/10.1016/ j.enggeo.2006.09.002.

Di Matteo L, Bigotti F and Ricco R (2009) Best-fit models to estimate modified Proctor properties of compacted soil. Journal of Geotechnical and Geoenvironmental Engineering 135(7): 992-996, https://doi.org/10.1061/(asce)gt.1943-5606.0000022.

Estabragh AR, Naseh M, Beytolahpour I and Javadi AA (2013) Strength of a clay soil and soil-cement mixture with resin. Proceedings of the Institution of Civil Engineers - Ground Improvement 166(2): 108-114, https://doi.org/10.1680/grim.12.00014.

Estabragh AR, Rafatjo $H$ and Javadi AA (2014) Treatment of an expansive soil by mechanical and chemical techniques. Geosynthetics International 21(3): 233-243, https://doi.org/ 10.1680/gein.14.00011.

Estabragh AR, Soltani A and Javadi AA (2016) Models for predicting the seepage velocity and seepage force in a fiber reinforced silty soil. Computers and Geotechnics 75: 174-181, https://doi.org/10.1016/ j.compgeo.2016.02.002.

Georgees RN, Hassan RA, Evans RP and Jegatheesan P (2015) Effect of the use of a polymeric stabilising additive on unconfined compressive strength of soils. Transportation Research Record 2473: 200-208, https://doi.org/10.3141/2473-23.

Gurtug Y and Sridharan A (2002) Prediction of compaction characteristics of fine-grained soils. Géotechnique 52(10): 761-763, https://doi.org/10.1680/geot.2002.52.10.761.

Gurtug $Y$ and Sridharan A (2004) Compaction behaviour and prediction of its characteristics of fine grained soils with particular reference to compaction energy. Soils and Foundations 44(5): 27-36, https://doi.org/10.3208/sandf.44.5_27.

Gurtug Y, Sridharan A and ikizler SB (2018) Simplified method to predict compaction curves and characteristics of soils. Iranian Journal of Science and Technology, Transactions of Civil Engineering, in press, https://doi.org/10.1007/s40996-018-0098-z.

Jha AK and Sivapullaiah PV (2016) Gypsum-induced volume change behavior of stabilised expansive soil with fly ash-lime. Geotechnical Testing Journal 39(3): 391-406, https://doi.org/10.1520/ gtj20150017. 
Kalkan E (2013) Preparation of scrap tire rubber fiber-silica fume mixtures for modification of clayey soils. Applied Clay Science 80-81: 117-125, https://doi.org/10.1016/j.clay.2013.06.014.

Kim S and Palomino AM (2009) Polyacrylamide-treated kaolin: a fabric study. Applied Clay Science 45(4): 270-279, https://doi.org/ 10.1016/j.clay.2009.06.009.

Kua TA, Arulrajah A, Mohammadinia A, Horpibulsuk S and Mirzababaei M (2017) Stiffness and deformation properties of spent coffee grounds based geopolymers. Construction and Building Materials 138: 79-87, https://doi.org/10.1016/j.conbuildmat.2017.01.082.

Mirzababaei M, Yasrobi SS and Al-Rawas AA (2009) Effect of polymers on swelling potential of expansive soils. Proceedings of the Institution of Civil Engineers - Ground Improvement 162(3): 111-119, https://doi.org/10.1680/grim.2009.162.3.111.

Mirzababaei M, Miraftab M, Mohamed M and McMahon P (2013a) Unconfined compression strength of reinforced clays with carpet waste fibers. Journal of Geotechnical and Geoenvironmental Engineering 139(3): 483-493, https://doi.org/10.1061/ (asce)gt.1943-5606.0000792.

Mirzababaei M, Miraftab M, Mohamed M and McMahon P (2013b) Impact of carpet waste fibre addition on swelling properties of compacted clays. Geotechnical and Geological Engineering 31(1): 173-182, https://doi.org/10.1007/s10706-012-9578-2.

Mirzababaei M, Arulrajah A, Horpibulsuk S and Aldavad M (2017) Shear strength of a fibre-reinforced clay at large shear displacement when subjected to different stress histories. Geotextiles and Geomembranes 45(5): 422-429, https://doi.org/10.1016/ j.geotexmem.2017.06.002.

Mirzababaei M, Mohamed M, Arulrajah A, Horpibulsuk S and Anggraini V (2018) Practical approach to predict the shear strength of fibre-reinforced clay. Geosynthetics International 25(1): 50-66, https://doi.org/10.1680/jgein.17.00033.

Mitchell JK and Soga K (2005) Fundamentals of Soil Behavior, 3rd edn. John Wiley \& Sons, Hoboken, NJ, USA.

Nagaraj HB, Reesha B, Sravan MV and Suresh MR (2015) Correlation of compaction characteristics of natural soils with modified plastic limit. Transportation Geotechnics 2: 65-77, https://doi.org/ 10.1016/j.trgeo.2014.09.002.

Özkul ZH and Baykal G (2007) Shear behavior of compacted rubber fiber-clay composite in drained and undrained loading. Journal of Geotechnical and Geoenvironmental Engineering 133(7): 767-781, https://doi.org/10.1061/(asce)1090-0241(2007)133:7(767).

Pandian NS, Nagaraj TS and Manoj M (1997) Re-examination of compaction characteristics of fine-grained soils. Géotechnique 47(2): 363-366, https://doi.org/10.1680/geot.1997.47.2.363.

Perez JL, Kwok CY and Senetakis K (2017) Investigation of the micromechanics of sand-rubber mixtures at very small strains. Geosynthetics International 24(1): 30-44, https://doi.org/ 10.1680/jgein.16.00013.

Pillai GAS and Vinod PP (2016) Re-examination of compaction parameters of fine-grained soils. Proceedings of the Institution of Civil Engineers - Ground Improvement 169(3): 157-166, https://doi.org/10.1680/jgrim.15.00005.

Prakash K and Sridharan A (2006) Critical appraisal of the cone penetration method of determining soil plasticity. Canadian Geotechnical Journal 43(8): 884-888, https://doi.org/10.1139/ t06-043.

Prakash K and Sridharan A (2012) Classification of non-plastic soils. Indian Geotechnical Journal 42(2): 118-123, https://doi.org/ 10.1007/s40098-012-0007-5.

Priyadarshee A, Kumar A, Gupta D and Pushkarna P (2018) Compaction and strength behavior of tire crumbles-fly ash mixed with clay. Journal of Materials in Civil Engineering 30(4): 04018033, https://doi.org/10.1061/(asce)mt.19435533.0002171
SA (Standards Australia) (2009a) AS 1289.3.2.1-09: Methods of testing soils for engineering purposes: soil classification tests determination of the plastic limit of a soil. Standards Australia, Sydney, NSW, Australia.

SA (2009b) AS 1289.3.3.1-09: Methods of testing soils for engineering purposes: soil classification tests - calculation of the plasticity index of a soil. Standards Australia, Sydney, NSW, Australia.

SA (2015) AS 1289.3.9.1-15: Methods of testing soils for engineering purposes: soil classification tests - determination of the cone liquid limit of a soil. Standards Australia, Sydney, NSW, Australia.

Seda JH, Lee JC and Carraro JAH (2007) Beneficial use of waste tire rubber for swelling potential mitigation in expansive soils. In Geo-Denver 2007: Soil Improvement (Schaefer VR, Filz GM, Gallagher PM, Sehn AL and Wissmann KJ (eds)). American Society of Civil Engineers, Reston, VA, USA, GSP 172, pp. 1-9, https://doi.org/10.1061/40916(235)5.

Signes $\mathrm{CH}$, Garzón-Roca J, Fernández PM, Torre MEG and Franco RI (2016) Swelling potential reduction of Spanish argillaceous marlstone Facies Tap soil through the addition of crumb rubber particles from scrap tyres. Applied Clay Science 132-133: 768-773, https://doi.org/10.1016/j.clay.2016.07.027.

Sivrikaya O, Togrol E and Kayadelena C (2008) Estimating compaction behavior of fine-grained soils based on compaction energy. Canadian Geotechnical Journal 45(6): 877-887, https://doi.org/ 10.1139/t08-022.

Soltani A, Taheri A, Khatibi M and Estabragh AR (2017a) Swelling potential of a stabilised expansive soil: a comparative experimental study. Geotechnical and Geological Engineering 35(4): 1717-1744, https://doi.org/10.1007/s10706-017-0204-1.

Soltani A, Deng A, Taheri A and Mirzababaei M (2017b) A sulphonated oil for stabilisation of expansive soils. International Journal of Pavement Engineering, in press, https://doi.org/10.1080/10298436. 2017.1408270 .

Soltani A, Deng A and Taheri A (2018a) Swell-compression characteristics of a fiber-reinforced expansive soil. Geotextiles and Geomembranes 46(2): 183-189, https://doi.org/10.1016/ j.geotexmem.2017.11.009.

Soltani A, Deng A, Taheri A and Mirzababaei M (2018b) Rubber powder-polymer combined stabilisation of South Australian expansive soils. Geosynthetics International 25(3): 304-321, https://doi.org/10.1680/jgein.18.00009.

Soltani A, Deng A, Taheri A and Sridharan A (2018c) Swell-shrinkconsolidation behavior of rubber-reinforced expansive soils. Geotechnical Testing Journal, in press, https://doi.org/10.1520/ gtj20170313.

Soltani A, Deng A, Taheri A, Sridharan A and Estabragh AR (2018d) A framework for interpretation of the compressibility behavior of soils. Geotechnical Testing Journal 41(1): 1-16, https://doi.org/ 10.1520/gtj20170088.

Soosan TG, Sridharan A, Jose BT and Abraham BM (2005) Utilisation of quarry dust to improve the geotechnical properties of soils in highway construction. Geotechnical Testing Journal 28(4): 391-400, https://doi.org/10.1520/gtj11768.

Sridharan A and Nagaraj HB (2005) Plastic limit and compaction characteristics of fine-grained soils. Proceedings of the Institution of Civil Engineers - Ground Improvement 9(1): 17-22, https:/ doi.org/10.1680/grim.2005.9.1.17.

Sridharan A and Sivapullaiah PV (2005) Mini compaction test apparatus for fine grained soils. Geotechnical Testing Journal 28(3): 240-246, https://doi.org/10.1520/gtj12542.

Sridharan A, Nagaraj HB and Prakash K (1999) Determination of the plasticity index from flow index. Geotechnical Testing Journal 22(2): 175-181, https://doi.org/10.1520/gtj11276j.

Srivastava A, Pandey S and Rana J (2014) Use of shredded tyre waste in improving the geotechnical properties of expansive black cotton 
soil. Geomechanics and Geoengineering 9(4): 303-311, https:/l doi.org/10.1080/17486025.2014.902121.

Tang CS, Shi B and Zhao LZ (2010) Interfacial shear strength of fiber reinforced soil. Geotextiles and Geomembranes 28(1): 54-62, https://doi.org/10.1016/j.geotexmem.2009.10.001.

Trouzine H, Bekhiti M and Asroun A (2012) Effects of scrap tyre rubber fibre on swelling behaviour of two clayey soils in Algeria. Geosynthetics International 19(2): 124-132, https://doi.org/10.1680/ gein.2012.19.2.124.

Wang YX, Guo PP, Ren WX et al. (2017) Laboratory investigation on strength characteristics of expansive soil treated with jute fiber reinforcement. International Journal of Geomechanics 17(11): 04017101, https://doi.org/10.1061/(asce)gm.1943-5622. 0000998.

Wang C, Deng A and Taheri A (2018) Three-dimensional discrete element modeling of direct shear test for granular rubber-sand.
Computers and Geotechnics 97: 204-216, https://doi.org/10.1016/ j.compgeo.2018.01.014.

Wroth CP and Wood DM (1978) The correlation of index properties with some basic engineering properties of soils. Canadian Geotechnical Journal 15(2): 137-145, https://doi.org/10.1139/ t78-014.

Yadav JS and Tiwari SK (2017a) A study on the potential utilisation of crumb rubber in cement treated soft clay. Journal of Building Engineering 9: 177-191, https://doi.org/10.1016/j.jobe.2017.01.001.

Yadav JS and Tiwari SK (2017b) Effect of waste rubber fibres on the geotechnical properties of clay stabilised with cement. Applied Clay Science 149: 97-110, https://doi.org/10.1016/j.clay.2017.07.037.

Yadav JS and Tiwari SK (2017c) The impact of end-of-life tires on the mechanical properties of fine-grained soil: a review. Environment, Development and Sustainability, in press, https://doi.org/ 10.1007/s10668-017-0054-2.

\section{How can you contribute?}

To discuss this paper, please email up to 500 words to the editor at journals@ice.org.uk. Your contribution will be forwarded to the author(s) for a reply and, if considered appropriate by the editorial board, it will be published as discussion in a future issue of the journal.

Proceedings journals rely entirely on contributions from the civil engineering profession (and allied disciplines). Information about how to submit your paper online is available at www.icevirtuallibrary.com/page/authors, where you will also find detailed author guidelines. 